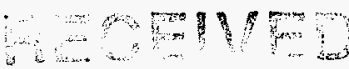 \\ DEC 301350 \\ OSTI
}

\section{EVALUATION OF COBALT MOBILITY IN SOILS FROM THE NEVADA TEST SITE}

\author{
prepared by
}

Charalambos Papelis

submitted to

Nevada Operations Office

U.S. Department of Energy

September 1996

DWTISUTION OF THIS DOCURENT IS UNLIMTED 


\section{DISCLAIMER}

Portions of this document may be illegible in electronic image products. Images are produced from the best available original document. 
This report was prepared as an account of work sponsored by the United States Government. Neither the United States nor the United States Department of Energy, nor any of their employees, makes any warranty, express or implied, or assumes any legal liability or responsibility for the accuracy, completeness or usefulness of any information, apparatus, product or process disclosed, or represents that its use would not infringe privately owned rights. Reference herein to any specific commercial product, process, or service by trade name, mark, manufacturer, or otherwise, does not necessarily constitute or imply its endorsement, recommendation, or favoring by the United States Government or any agency thereof. The views and opinions of authors expressed herein do not necessarily state or reflect those of the United States Government or any agency thereof.

This report has been reproduced directly from the best available copy.

Available to DOE and DOE contractors from the Office of Scientific and Technical Information, P.O. Box 62, Oak Ridge, TN 37831; prices available from (615) 576-8401.

Available to the public from the National Technical Information Service, U.S. Department of Commerce, 5285 Port Royal Rd., Springfield, VA 22161. 


\title{
EVALUATION OF COBALT MOBILITY IN SOILS FROM THE NEVADA TEST SITE
}

\author{
prepared by \\ Charalambos Papelis \\ Water Resources Center \\ Desert Research Institute \\ University and Community College System of Nevada
}

Publication No. 45140

submitted to

Nevada Operations Office

U.S. Department of Energy

Las Vegas, Nevada

September 1996

The work upon which this report is based was supported by the U.S. Department of Energy under Contract \#DE-AC08-95NV11508. 


\begin{abstract}
Nuclear testing at and around the Nevada Test Site (NTS) resulted in widespread contamination from transuranic and other radionuclides, as well as from other toxic inorganic and organic contaminants. The type of contamination, including spatial distribution and type of radionuclides present, depends on the type of testing performed. Remediation of the contaminated areas is currently under way. The optimum in situ or ex situ remediation technology depends on the degree of interaction between the particular radionuclide, or contaminant in general, and the soil matrix, among other factors. The objective of this project was to evaluate the sorption affinity of NTS soils for common non-transuranic radionuclides. The sorption of cobalt $(\mathrm{Co})$ on soils from two different areas of the NTS, namely the Little Feller and Cabriolet event sites, was studied. Experiments were conducted as a function of $\mathrm{pH}$, solid concentration, total Co concentration, ionic strength, and particle size fraction. Preliminary results indicate that both soils have a high sorption capacity for $\mathrm{Co}$. The results suggest that $\mathrm{Co}$ uptake is controlled by sorption on either internal, permanent-charge, ion-exchange sites of clay minerals or on amphoteric, surface-hydroxyl sites of oxides. The results further indicate strong retardation of $\mathrm{Co}$ in these soils, under most conditions tested and expected to be found in the respective soil environments. These conclusions are applicable to transport of radionuclides which are expected to bind strongly on oxide surfaces (e.g., Co) but the results may not be representative of the behavior of weakly binding radionuclides. These studies clearly demonstrate the importance of evaluating the mobility of radionuclides and the degree of radionuclide-soil interaction before final selection of an in situ or ex situ remediation technology for a contaminated site.
\end{abstract}




\section{ACKNOWLEDGMENTS}

The technical assistance of MaryAnn Reeder and Itai Segev with the experimental part of the project is gratefully acknowledged. The continued support of Monica Sanchez is greatly appreciated. The comments of Roger Jacobson, Sam Hokett, and Lynn Shaulis improved the report and are also acknowledged. The skillful word processing and graphics work of Rebecca Gardiner are gratefully acknowledged. 


\section{EXECUTIVE SUMMARY}

During the period of nuclear weapon production and testing, the U.S. conducted a series of nuclear tests at the Nevada Test Site (NTS). These tests resulted in widespread contamination of large areas from both uranium and transuranic elements (man-made radionuclides heavier than uranium), such as neptunium, plutonium, and americium, as well as from radioactive isotopes of lighter elements, typical fission products of the heavier elements. In addition to radioisotopes, substantial quantities of non-radioactive, hazardous inorganic materials, such as lead, copper, arsenic, chromium, and cadmium, and possibly organic compounds such as PVC, polystyrene, and phenols, were also released. Because of the potential health hazards associated with these compounds, several areas of the NTS are included in the proposed remediation plan of the U.S. Department of Energy/Nevada Operations Office (DOE/NV).

The most appropriate remediation technology is a function of the type of contamination present. Contamination associated with small, clay-sized particles may be particularly hazardous because of increased exposure potential. If the contaminants are associated with particles of the top soil only, displacement or removal of contaminants from the accessible top fraction of the soil would substantially reduce the danger of exposure so that the area could possibly be regarded as sufficiently remediated. Such an approach would only be feasible if the mobility of the contaminant of concern were sufficiently high. Contaminants strongly bound to mineral surfaces would be prohibitively immobile for such a remediation scheme. Although increased ion mobility may be beneficial with respect to contaminant removal from the top soil surface layer and hazard reduction, it can also result in contaminant spreading beyond acceptable limits and increased risk of contamination of underlying aquifers.

Before adopting any in situ or ex situ (e.g., soil washing) remediation technology, an understanding of the interactions between the contaminants present and the soils to be remediated would be necessary. In this study, the sorption of cobalt $(\mathrm{Co})$ on two types of soils from the NTS was investigated. Cobalt was selected because it is a commonly found and representative medium-weight radioisotope; in addition, its interactions with several well-characterized minerals have been studied extensively. The two types of soil samples received from the NTS came from the Cabriolet and Little Feller event sites, which represent two of the areas likely to be targeted for remediation. To evaluate the mobility of Co in the soils of the two areas, a parametric sorption study was conducted. Experimental variables included soil type, $\mathrm{pH}$, solid concentration, metal concentration, ionic strength, and particle size fraction. In addition, a physicochemical, albeit limited, characterization of the soil was conducted. Additional soil characterization would have been helpful but could not be performed because of time and budgetary constraints. Additional effort spent on soil characterization would help confirm the explanations of the observed sorption behavior which are presented here.

Preliminary results suggest that, under most experimental conditions, Co sorbs strongly on the soils studied. The extent of sorption appears to be a combination of experimental conditions, primarily $\mathrm{pH}$, particle size distribution, and ionic strength. The results reported here indicate that at least two distinct types of sites exist in these soils and contribute to the observed sorption behavior: ion-exchange (permanent-charge) sites on smectite clay minerals and 
amphoteric (surface-hydroxyl) sites on oxides and oxide coatings, as well as on the edges of the clay particles. With decreasing particle size, the relative abundance of clay minerals (on a per-mass basis) is expected to increase. In the smaller particle size fraction (particles smaller than $45 \mathrm{~mm}$ ), therefore, sorption is probably controlled by clay minerals, a fact reflected in the relatively high ionic strength dependence of sorption. In the coarser size fraction (all particles smaller than $1,180 \mathrm{~mm}$ ), the relative abundance of clay minerals (and therefore ion-exchange sites) is lower and the observed ionic-strength dependence of sorption is also reduced. The reported results indicate that Co is quantitatively (at least $90 \%$ ) sorbed on these soils, when the equilibrium $\mathrm{pH}$ is above 7 and the solid concentration is at least $20 \mathrm{~g} / \mathrm{L}$. Given that the soil solution $\mathrm{pH}$ of these soils is approximately 8 , Co is expected to bind strongly on these soils under typical environmental conditions.

These results suggest that displacement of radionuclides similar to Co to deeper areas of the soil profile would probably be impractical and that other remediation technologies need to be investigated. Evaluation of any proposed remediation technology, however, would require additional experimental studies using parameters reflecting the actual concentrations of radionuclides present and hydrodynamic conditions expected to be encountered in the field.

Based on the results from this study, the following recommendations can be made. As mentioned earlier, additional characterization of the soils is needed to provide information related to mineral composition and physicochemical properties of the soils, such as surface area, porosity, and particle morphology. The mineral composition studies would be used to estimate the relative abundance of different types of sorption sites, a requirement for understanding the observed sorption behavior. Additional soil characterization studies are needed to determine the presence of iron, manganese, or organic coatings, all of which can significantly influence the sorption behavior of cations.

The preliminary experiments reported here suggest that Co binds strongly on the NTS soils studied. Experiments with other cations, however, in addition to Co should be conducted to evaluate the mobility of other important radionuclide contaminants, such as strontium and cesium. Such experiments would be necessary because these cations form substantially weaker surface complexes on oxides. Experiments with these additional contaminants, which are likely to demonstrate sorption behavior different from $\mathrm{Co}$, would provide the necessary experimental background for any attempted soil remediation technology. In addition, experiments with important anionic contaminants, such as chromates, should be performed to evaluate the mobility and remediation potential for these contaminants. Finally, the batch sorption experiments reported here should be complemented by column experiments using the same contaminants and soils. The scope of these additional studies would be to realistically simulate contaminant migration and to explore in situ and ex situ remediation alternatives by coupling solute-mineral surface interactions with vertical particle movement. 


\section{CONTENTS}

ABSTRACT $\ldots \ldots \ldots \ldots \ldots \ldots \ldots \ldots \ldots \ldots \ldots \ldots \ldots \ldots \ldots \ldots \ldots \ldots \ldots$

ACKNOWLEDGMENTS $\ldots \ldots \ldots \ldots \ldots \ldots \ldots \ldots \ldots \ldots \ldots \ldots \ldots \ldots \ldots \ldots$ ii

EXECUTIVE SUMMARY $\ldots \ldots \ldots \ldots \ldots \ldots \ldots \ldots \ldots \ldots \ldots \ldots \ldots \ldots \ldots \ldots \ldots$ iii

FIGURES $\ldots \ldots \ldots \ldots \ldots \ldots \ldots \ldots \ldots \ldots \ldots \ldots \ldots \ldots \ldots \ldots \ldots \ldots \ldots$ vi

TABLES $\ldots \ldots \ldots \ldots \ldots \ldots \ldots \ldots \ldots \ldots \ldots \ldots \ldots \ldots \ldots \ldots \ldots \ldots \ldots$

INTRODUCTION $\ldots \ldots \ldots \ldots \ldots \ldots \ldots \ldots \ldots \ldots \ldots \ldots \ldots \ldots \ldots \ldots \ldots$

THEORETICAL BACKGROUND $\ldots \ldots \ldots \ldots \ldots \ldots \ldots \ldots \ldots \ldots \ldots \ldots \ldots \ldots$

EXPERIMENTAL PROCEDURES $\ldots \ldots \ldots \ldots \ldots \ldots \ldots \ldots \ldots \ldots \ldots \ldots \ldots$

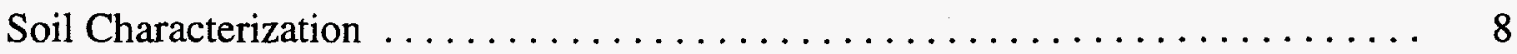

Materials and Methods . . . . . . . . . . . . . . . 12

RESULTS AND DISCUSSION $\ldots \ldots \ldots \ldots \ldots \ldots \ldots \ldots \ldots \ldots \ldots \ldots \ldots \ldots \ldots$

SUMMARY, CONCLUSIONS, AND RECOMMENDATIONS $\ldots \ldots \ldots \ldots \ldots \ldots \ldots$

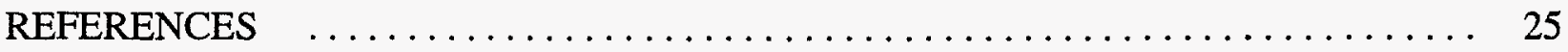

APPENDIX A: Experimental Data and Fractional Uptake of Co by Cabriolet Soil ....... 27

APPENDIX B: Experimental Data and Fractional Uptake of Co by Little Feller Soil ..... 28 


\section{FIGURES}

1. Map of the NTS showing the locations of Cabriolet and Little Feller event sites. ... 3

2. Schematic representation of surface complexes. ................. 5

3. Schematic representation of the solid-liquid interface. $\ldots \ldots \ldots \ldots \ldots \ldots \ldots$

4. Cumulative percentage mass distribution. $\ldots \ldots \ldots \ldots \ldots \ldots \ldots \ldots \ldots \ldots \ldots \ldots \ldots \ldots$

5. Co sorption on Cabriolet soil as a function of ionic strength. ........... 15

6. Co sorption on Cabriolet soil as a function of metal concentration. .......... 18

7. Summary of Co sorption results on $20 \mathrm{~g} / \mathrm{L}$ of Cabriolet soil. $\ldots \ldots \ldots \ldots \ldots$

8. Co sorption on Little Feller soil as a function of metal concentration. ......... 20

9. Summary of Co sorption results on $20 \mathrm{~g} / \mathrm{L}$ of Little Feller soil. .......... 21

10. Comparison of Cabriolet and Little Feller Co sorption data; $\mathrm{I}=0.1 \mathrm{M}, \mathrm{d}<1,180 \mu \mathrm{m} . \quad$. 21

\section{TABLES}

1. Particle-size Distribution of Soils. . . . . . . . . . . . . . . . . 10

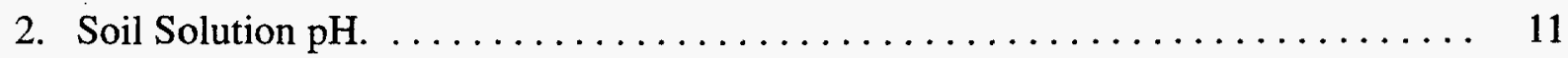




\section{INTRODUCTION}

During the period of nuclear weapon production and testing, the U.S. conducted a series of tests at the Nevada Test Site (NTS). Tests were conducted by detonation of nuclear devices either at the surface or underground. These tests included both detonations using conventional explosives, to assess the possibility of an accidental nuclear explosion, and planned nuclear explosions. Both types of tests resulted in widespread contamination from radionuclides as well as from other toxic metals at the surface and underground. Radionuclides included both uranium and heavy transuranic elements (man-made radionuclides heavier than uranium), such as neptunium, plutonium, and americium, as well as radioactive isotopes of lighter elements, typically fission products of the heavier elements. In addition, the tests resulted in the release of substantial quantities of non-radioactive, hazardous inorganic materials, such as lead, copper, arsenic, chromium, and cadmium, and possibly organic compounds such as PVC, polystyrene, and phenols. These contaminants are considered health hazards either because of their toxicity or because they are either suspected or proven carcinogens (Francis, 1994; Sax, 1981).

The health hazard potential of these contaminants depends on the pathway by which they enter the biosphere and, specifically, the potential pathway by which they may enter the human body. The risk from inhalation is generally believed to be higher than the risk from ingestion. The more likely pathway by which contaminants may enter the human body is partly determined by the type of contamination. Surface contamination associated with fine, clay-size particles is considered particularly hazardous because of the potential of dust formation in the Nevada desert and subsequent increased exposure. The health hazard potential from ingestion would be higher for mobile radionuclides and other toxic elements, if the migration of such contaminants resulted in contamination of underlying aquifers.

The fate and transport of individual contaminants are largely determined by the degree of contaminant interaction with the soil matrix. Radionuclides and metals with high sorption affinity for the mineral phases present tend to be severely retarded compared to groundwater flow. Inorganic contaminants with little affinity for the mineral surfaces present are retarded significantly less and, in the ideal case of truly conservative ions, they move essentially with groundwater velocity. Estimation of the time required for a particular type of contaminant to reach the accessible environment, therefore, requires studying the potential interactions between the particular contaminant and the solid phases likely to be encountered in a given flowpath.

In addition to being able to predict the potential for migration of radionuclides and other contaminants, studies of interactions between environmental contaminants at the NTS and the natural soils are crucial for selecting an appropriate remediation technology for these soils. For example, if it is determined that most of the existing surface contamination is limited to the top few centimeters of soil, a possible remediation technology might include an attempt to flush such contaminants to deeper layers by application of an aqueous solution. Such a remediation technology might be considerably less expensive than disposal of large quantities of contaminated soil as hazardous waste, but it may be all that is required to remove contaminants from the accessible 
environment. The conditions under which such an approach might be successful are directly related to the degree of interaction between the contaminants of concern and the NTS soil. Strongly binding ions may require prohibitively large quantities for breakthrough past a certain point of the soil profile. Weakly binding ions, however, may be transported at much higher rates and possibly contaminate nearby aquifers.

Similar considerations would also be important if an alternative technology were proposed, such as incorporation of contaminants in man-made or natural cements, because the ability of the cement to retain specific ions would be most likely related to the strength of surface complexes formed between the ions and the mineral surfaces. The bonding strength may vary significantly for different ions, as will be stated in more detail in subsequent sections. Therefore, preliminary investigations of contaminant-soil interactions at the NTS appear to be necessary. These investigations would normally progress from simple, bench-scale, laboratory equilibrium experiments to assess the relative affinity of contaminants of concern for NTS soils, to rate-of-uptake and column experiments to assess the rate at which these processes occur under controlled laboratory conditions, before evaluation in a pilot-scale field study.

In the present study, sorption of cobalt (in the +II oxidation state, $\mathrm{Co}$ (II)) on soils from two areas of the NTS, namely from the Cabriolet and Little Feller event sites, was studied. Co was selected because it is one of the radionuclides most commonly found in contaminated sites, as it is a common fission product of the heavier elements. Because it is ubiquitous and toxic, Co chemistry and sorption behavior have been studied extensively. Soils from the Cabriolet and Little Feller locations were selected, representing two of the areas likely to be selected for remediation by the Environmental Restoration Division of the Department of Energy, Nevada Operations Office (DOE/NV). The general location of the Cabriolet and Little Feller sites on the NTS is shown in Figure 1.

Sorption experiments were conducted as a function of several geochemical parameters. These experiments provide valuable information regarding sorption of $\mathrm{Co}$ on Cabriolet and Little Feller soils. Unfortunately, however, because of budgetary constraints, additional experiments required to complete the set of experimental conditions and to completely understand the behavior of this element in this particular soil environment could not be performed. Additional experiments with at least a weakly binding cation, a strongly binding anion, and a weakly binding anion should also be performed to assess the capacity of the soil for ions with different sorption characteristics. These recommendations are also included in more detail in the final section of this report.

The remainder of this report is organized as follows. The section on theoretical background briefly reviews basic concepts and studies of trace metal surface geochemistry. It is not meant to be a detailed introduction to this vast subject, but is only meant to provide the minimum information necessary for understanding the results and discussion section and is included for the benefit of the reader. The soil characterization and the summary of the experimental procedures used in this study are presented in the section on experimental procedures, followed by results and discussion. The last 
section is a summary of the results, conclusions, and recommendations for further study. Finally, the Appendices include all raw experimental data and Co sorption calculations.

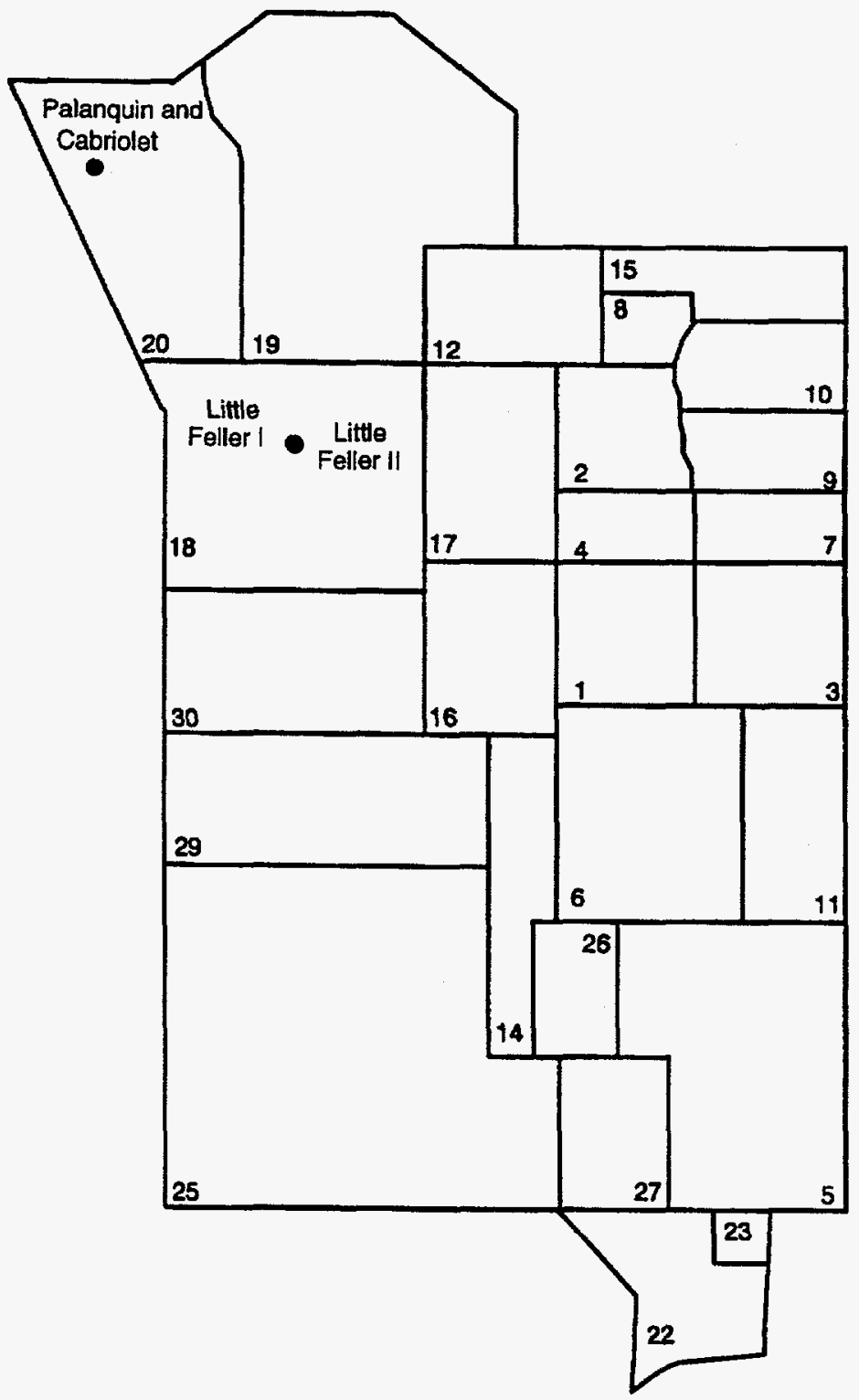

Figure 1. Map of the NTS showing the locations of Cabriolet and Little Feller event sites.

\section{THEORETICAL BACKGROUND}

It has long been established that the degree of inorganic contaminant interaction with mineral surfaces is a function of the adsorbate, the adsorbent, and other geochemical parameters, most importantly, pH and ionic strength (Davis and Hayes, 1986a; Hochella and White, 1990; McBride, 
1994; Stumm, 1992). Potential adsorbates could include radionuclides or any other inorganic contaminant of concern. These, moreover, could be either positively charged ions (cations) or negatively charged ions (anions). Any solid phase present, including crystalline, disordered, and amorphous phases, would constitute a possible adsorbent.

Sorption reactions by which a solute is partitioned between a solid and an aqueous phase are usually subdivided into adsorption, absorption, and surface precipitation reactions (Davis and Hayes, 1986b). Adsorption refers to accumulation of solute molecules at the solid-liquid interface, either as mononuclear or polynuclear complexes. Absorption refers to incorporation of solute molecules into the adsorbent matrix. Absorption of an ion by a mineral phase implies diffusion of the ion inside the mineral matrix. Necessarily, then, absorption follows adsorption of the adsorbate at the solid-liquid interface. Because diffusion processes in minerals are typically very slow, absorption of inorganic contaminants by mineral phases can only become important during later stages of the equilibration process. Absorption may, therefore, become a factor in the ultimate fate of radionuclides and inorganic contaminants in the environment, but is not likely to be important during the early stages of a sorption experiment.

Finally, surface precipitation refers to the formation of a separate three-dimensional phase on the substrate, as opposed to formation of a two-dimensional layer. The formation of a surface precipitate can occur at concentrations substantially below the solubility limit of the phase being formed. It is believed that the formation of a precipitate at concentrations not exceeding the solubility of a given phase is thermodynamically feasible because of the presence of the adsorbent which acts as a nucleation site (Sposito, 1986). A schematic representation of possible surface complexes is shown in Figure 2.

Sorption complexes can be further subdivided based on the bond strength between the sorbing ion and the mineral substrate. Ions which tend to retain their primary hydration sheath (water molecules directly coordinated to any dissolved species) during sorption are separated from the surface by at least a layer of water molecules and tend to form weaker bonds. These complexes are usually referred to as outer-sphere complexes, because it is only the outer hydration sphere of the ion which is involved in sorption. These ion-pair complexes are held to the surface mainly by electrostatic forces. Ions which lose part of their primary hydration sheath may approach the surface substantially closer and can form direct coordination complexes, equivalent to coordination complexes formed in solution. These complexes are directly bound to the surface and because the inner hydration sphere of the ion is involved in sorption, they are also referred to as inner-sphere complexes. Schematic representations of inner- and outer-sphere complexes are also shown in Figure 2.

Distinguishing between inner- and outer-sphere complexes, or essentially between strongly and weakly binding complexes, is a requirement for more accurate predictions of the fate and transport of contaminants in the environment. Outer-sphere complexes are loosely retained by the surface and are therefore fairly mobile, whereas inner-sphere complexes are held strongly and therefore tend to be substantially retarded compared to water movement. Breakthrough of weakly 


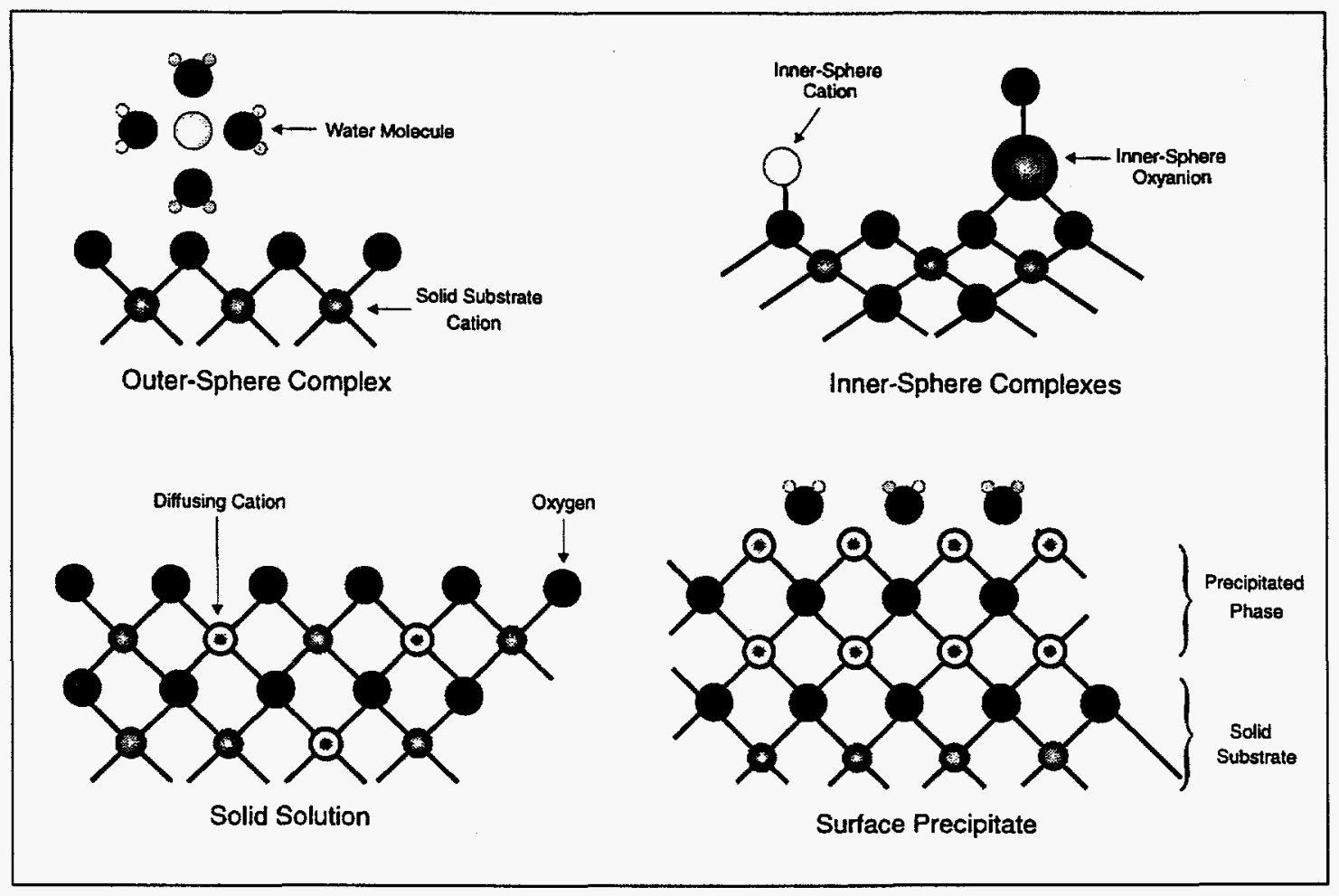

Figure 2. Schematic representation of surface complexes.

bound ions at a certain distance from the source of contamination is therefore expected to occur substantially faster than that for strongly sorbing ions. The type of surface complex formed, however, is a combination of both adsorbent and adsorbate and any given adsorbate may form complexes of varying strength on different adsorbents. The relative affinity of individual sorbates for different sorbents is related to the coordination chemistry of the sorbent and the tendency of the sorbate to hydrolyze (Stumm, 1992). The surface of several classes of minerals, however, typically has more than one type of sites, forming surface complexes of different strength with any given ion.

Examples of minerals with multiple types of sites can be found among common classes of sorbing mineral phases, such as oxides, hydroxides, and clay minerals. The oxide goethite $(\alpha-\mathrm{FeOOH})$ and hydroxide gibbsite $\left(\gamma-\mathrm{Al}(\mathrm{OH})_{3}\right)$, for example, two very common iron and aluminum minerals, respectively, have at least three types of surface hydroxyls with greatly varying reactivities (Sposito, 1984). The most reactive sites of these minerals account for essentially all sorption measured. These surface hydroxyl sites act like polyprotic acids in solution, i.e., they can be protonated or deprotonated and exchange hydrogen and hydroxyl ions with sorbates to form surface complexes, as is schematically shown in Figure 3.

Clay minerals, and specifically sheet silicates (phyllosilicates), composed of layers of silica tetrahedra and alumina octahedra, may also have multiple types of sites with different reactivities. 


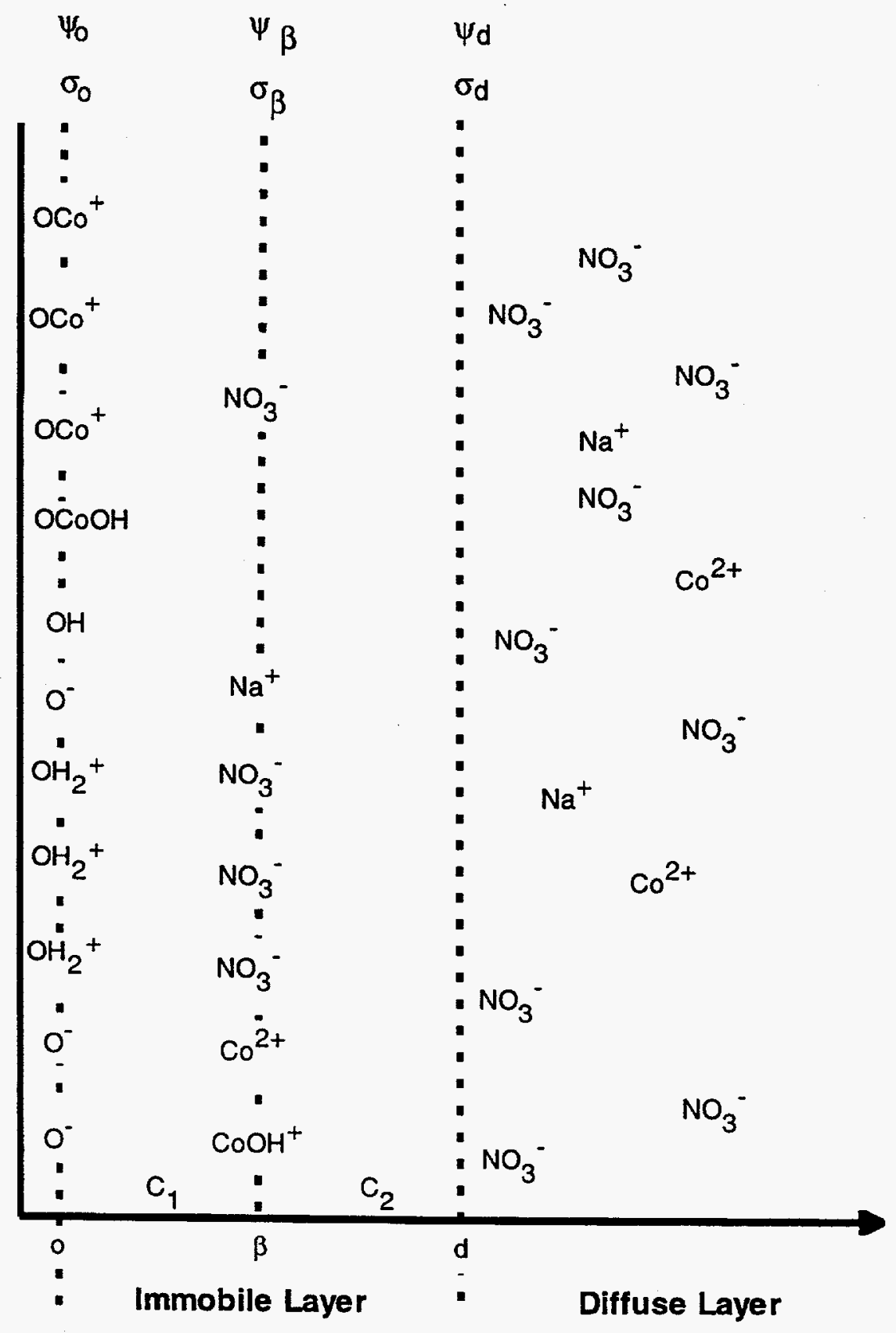

Figure 3. Schematic representation of the solid-liquid interface.

(See Klein and Hurlbut (1993) for an introductory description of the structure of these minerals.) Common non-expanding clays, like kaolinite, have sites of different reactivity associated with the silica tetrahedra and alumina octahedra. Expanding phyllosilicates (smectites), e.g., the common mineral montmorillonite, also have two distinct types of sites associated with the surface-hydroxyl sites at the edge of the sheet-like mineral structure and the tetrahedral interlayer sites between sheets. 
The edge sites are not distinguishable from the surface-hydroxyl sites on oxide surfaces, as described above, where cations and anions can sorb as either inner- or outer-sphere complexes. Reactive sites at the interlayer spacings of smectites carry a negative charge because of isomorphic substitutions of metal ions with lower charge for the aluminum and silicon ions (e.g., substitution of $\mathrm{Mg}^{2+}$ or Fe ${ }^{2+}$ for $\mathrm{Al}^{3+}$ and $\mathrm{Al}^{3+}$ for $\mathrm{Si}^{4+}$ ). Because of the negative structural charge created by isomorphic substitution, cations are attracted to the interlayer spacings to neutralize the charge, which results in the cation-exchange properties of these minerals. The cations sorbed in interlayer regions are believed to form outer-sphere complexes in most cases (Sposito, 1984).

As mentioned above, it is important to determine whether specific ions form weak (outer-) or strong (inner-sphere) complexes on a particular mineral. The formation of outer-sphere complexes has been correlated with ionic-strength effects on the observed sorption behavior. It is assumed that at higher background electrolyte ion concentration, weakly bound ions would be displaced from sorption sites, so that increasing ionic strength would substantially suppress the observed fractional uptake for outer-sphere complexes. In contrast, ions forming strong, inner-sphere complexes cannot be displaced by background electrolyte ions, even at high background electrolyte concentrations. Fractional uptake, therefore, in the case of inner-sphere complexes is expected to be essentially ionic-strength independent.

This approach has been tested on a number of different systems, including sorption of weakly and strongly binding anions and cations on iron oxide minerals. Sorption of cations assumed to be forming outer-sphere complexes $\left(\mathrm{Ba}^{2+}\right)$ on goethite was substantially suppressed by increasing the ionic strength, whereas the fractional uptake of lead $\left(\mathrm{Pb}^{2+}\right)$, assumed to form inner-sphere complexes, was only minimally influenced by increased ionic strength (Hayes and Leckie, 1987). Similarly, ionic-strength effects on the sorption of selenite, an anion forming strong complexes with goethite and ferrihydrite, had very little impact on fractional uptake, whereas the fractional uptake of selenate, an anion forming much weaker complexes, was substantially reduced at higher ionic strengths (Hayes et al., 1988).

The correlation between the effects of ionic strength on fractional uptake and the closeness of approach of an ion to a mineral surface has been verified in a number of cases using spectroscopic techniques. For example, the coordination environment of selenite sorbed on goethite was found to be consistent with formation of inner-sphere complexes, whereas the coordination environment of selenate was found to be consistent with formation of outer-sphere complexes (Hayes et al., 1987). Similarly, it was determined that Co forms inner-sphere complexes on the surfaces of kaolinite and quartz, specifically mononuclear complexes at low surface coverages and polynuclear complexes and surface precipitates at higher surface coverages (O'Day et al., 1994a; 1994b). In addition, the effects of ionic strength on Co sorption on montmorillonite were studied by comparing macroscopic and spectroscopic experiments (Papelis and Hayes, 1996). It was determined that Co forms primarily outer-sphere complexes at interlayer, ion-exchange sites at low ionic strength, but at increasingly higher ionic strength it is progressively excluded from these sites and forms inner-sphere complexes at surface-hydroxyl sites. 
The above considerations relate only to equilibrium sorption of contaminants, without consideration for the time required to reach equilibrium or the mechanism involved. These questions are addressed by studying the kinetics of sorption reactions. In addition, a distinction should be made between sorption kinetics limited by intrinsic chemical reaction rate vs. sorption limited by mass transfer. It is often assumed that the overall sorption process involves at least two steps, namely approach of the sorbing ion to the surface followed by an attachment step. A third step might involve exchange of the sorbing ion with a surface moiety, such as a hydrogen or a hydroxyl ion (Hayes and Leckie, 1986; Stumm, 1992; Yasunaga and Ikeda, 1986). The first step represents mass transfer of the sorbing ion to the mineral surface, while the second and third steps represent the chemical reaction per se. The overall rate of ion sorption may be controlled by either mass transfer or the intrinsic rate of the chemical reaction. The attachment step is generally considered to be very rapid (Hayes and Leckie, 1986; Yasunaga and Ikeda, 1986), but the overall reaction rate may be controlled by the slower exchange step (Stumm, 1992).

\section{EXPERIMENTAL PROCEDURES}

\section{Soil Characterization}

Sorption experiments were performed with Co solutions and two different types of soils from the NTS, namely soils from the Cabriolet and Little Feller event sites. Unfortunately, because of budgetary and time constraints, a complete characterization of these soils was not possible. Ideally, the following characterization steps should be performed, at a minimum. Particle size distribution analysis is required to determine the distribution of mass as a function of particle size. Because particle surface area is inversely proportional to particle size and the sorbing capacity of a mineral phase is directly proportional to surface area, smaller size fractions are expected to have increasingly higher sorbing capacity than coarser size fractions, on a per-mass basis. In addition, different minerals, with different properties and sorption site types, are expected to be present at different percentages in different size fractions. Clay minerals, e.g., with a high cation-sorption capacity, are expected to dominate sorption behavior in smaller size fractions.

Surface area measurement of the different soil size fractions is required for estimation of the sorption capacity of the soil. The specific surface area increases with decreasing size. Surface area measurements are required so that experiments can be normalized with respect to total surface area for different size fractions and different types of soil. The specific surface area is typically estimated using $\mathrm{N}_{2}$-adsorption and the Brunauer, Emmett, and Teller (BET) theory (Brunauer et al., 1938; Gregg and Sing, 1982). This method, however, gives an unrealistically low estimate of surface area for expanding (swelling) clays (smectites), because the nonpolar nitrogen molecule cannot diffuse in the interlayer spacings of these minerals. The ethylene glycol monoethyl ether (EGME) method is typically used to estimate the total surface area of smectite clays (Carter et al., 1986). By comparing specific surface area measurements with both techniques, one can estimate the area associated with internal and external sites of clay minerals.

$\mathrm{X}$-ray diffraction (XRD) is performed to identify the mineral phases present. XRD analysis should ideally be performed with different size fractions to determine the mineral composition as 
a function of particle size, for the reasons stated above. It should be remembered, however, that XRD is a bulk sample analysis, i.e., the bulk composition of the sample can be determined in terms of the major phases present. XRD analysis may not be able to detect the presence of mineral phases present as coatings of other minerals. These coatings may be disproportionally important with respect to sorption behavior because they may represent a substantial fraction of the available surface area, even though they may only represent a small fraction of the total mass.

Additional, more specific analyses, including electron microscopy (EM) combined with energy dispersive spectroscopy (S(canning)EM/EDS and T(ransmission)EM/EDS) and surface sensitive techniques such as $\mathrm{x}$-ray photoelectron spectroscopy (XPS) and scanning Auger microscopy (SAM), can be used to determine the composition of such mineral coatings. Analyses for extractable iron and manganese should also be performed to complement these more expensive techniques and to provide a quantitative estimate of iron and manganese minerals present. The presence of these minerals as coatings can substantially influence the sorptive behavior of natural soils.

Additional characterization should include measurement of soil solution $\mathrm{pH}$ and conductivity. These measurements provide information about the acidity of the sorption sites, the presence of dissolved species in solution, and the type of minerals with which the solution is in equilibrium. All of these factors influence the sorptive characteristics of the soil. Analysis for organic content of the soil should also be performed because natural organic ligands may also influence metal ion complexation and sorption. As stated above, not all of these tests could be performed. The specific analyses performed with the two types of soil are described below.

One five-gallon bucket of each type of soil was received from a non-contaminated area of the NTS. The two soils appeared to be different upon visual inspection. Little Feller soil appeared to be lighter in color than Cabriolet soil. In addition, Cabriolet soil appeared to have a higher organic fraction content, evident by the presence of fragments of vegetation. The soil was dry sieved to remove the coarser size fractions and to determine the particle size distribution. The fraction larger than $1,180 \mu \mathrm{m}$ was discarded because the surface area of material larger than $1,180 \mu \mathrm{m}$ is insignificant compared to the total surface area of the sample. Sieving was performed using an automated Rotap ${ }^{\mathrm{TM}}$ sieving screen system using mostly international size screens. The standard sieving procedure included sieving for $10 \mathrm{~min}$ and using, at the most, $50 \mathrm{~g}$ of soil per batch. In all cases, before the initial sieving of any sample, a batch was sieved and discarded to clean the screens.

The screens used, the nominal sieve opening $(\mu \mathrm{m})$, the range of particle sizes retained by each screen, and the mass and cumulative mass distributions among size fractions for the two soils are shown in Table 1. The particle size distribution, in terms of cumulative percentage of total soil mass, is also graphically shown in Figure 4. 
TABLE 1. PARTICLE-SIZE DISTRIBUTION OF SOILS.

\begin{tabular}{ccccccc}
\hline & & & \multicolumn{2}{c}{ Cabriolet } & \multicolumn{2}{c}{ Little Feller } \\
Sieve & $\begin{array}{c}\text { Particle Size } \\
\text { Retained } \\
(\mu \mathrm{m})\end{array}$ & $\begin{array}{c}\text { Percent } \\
\text { Total } \\
\text { Mass }\end{array}$ & $\begin{array}{c}\text { Cumulative } \\
\text { Percent } \\
\text { Total Mass }\end{array}$ & $\begin{array}{c}\text { Percent } \\
\text { Total } \\
\text { Mass }\end{array}$ & $\begin{array}{c}\text { Cumulative } \\
\text { Percent } \\
\text { Total Mass }\end{array}$ \\
\hline \hline & & $\mathrm{d}<45$ & 2.40 & 2.40 & 2.79 & 2.79 \\
325 & 45 & $45<\mathrm{d}<63$ & 8.93 & 11.33 & 10.56 & 13.35 \\
230 & 63 & $63<\mathrm{d}<90$ & 9.71 & 21.04 & 10.02 & 23.37 \\
170 & 90 & $90<\mathrm{d}<125$ & 10.68 & 31.72 & 14.17 & 37.54 \\
120 & 125 & $125<\mathrm{d}<250$ & 20.82 & 52.54 & 25.07 & 62.61 \\
60 & 250 & $250<\mathrm{d}<600$ & 28.66 & 81.20 & 22.25 & 84.85 \\
30 & 600 & $600<\mathrm{d}<1180$ & 18.80 & 100.00 & 15.15 & 100.00 \\
\hline
\end{tabular}

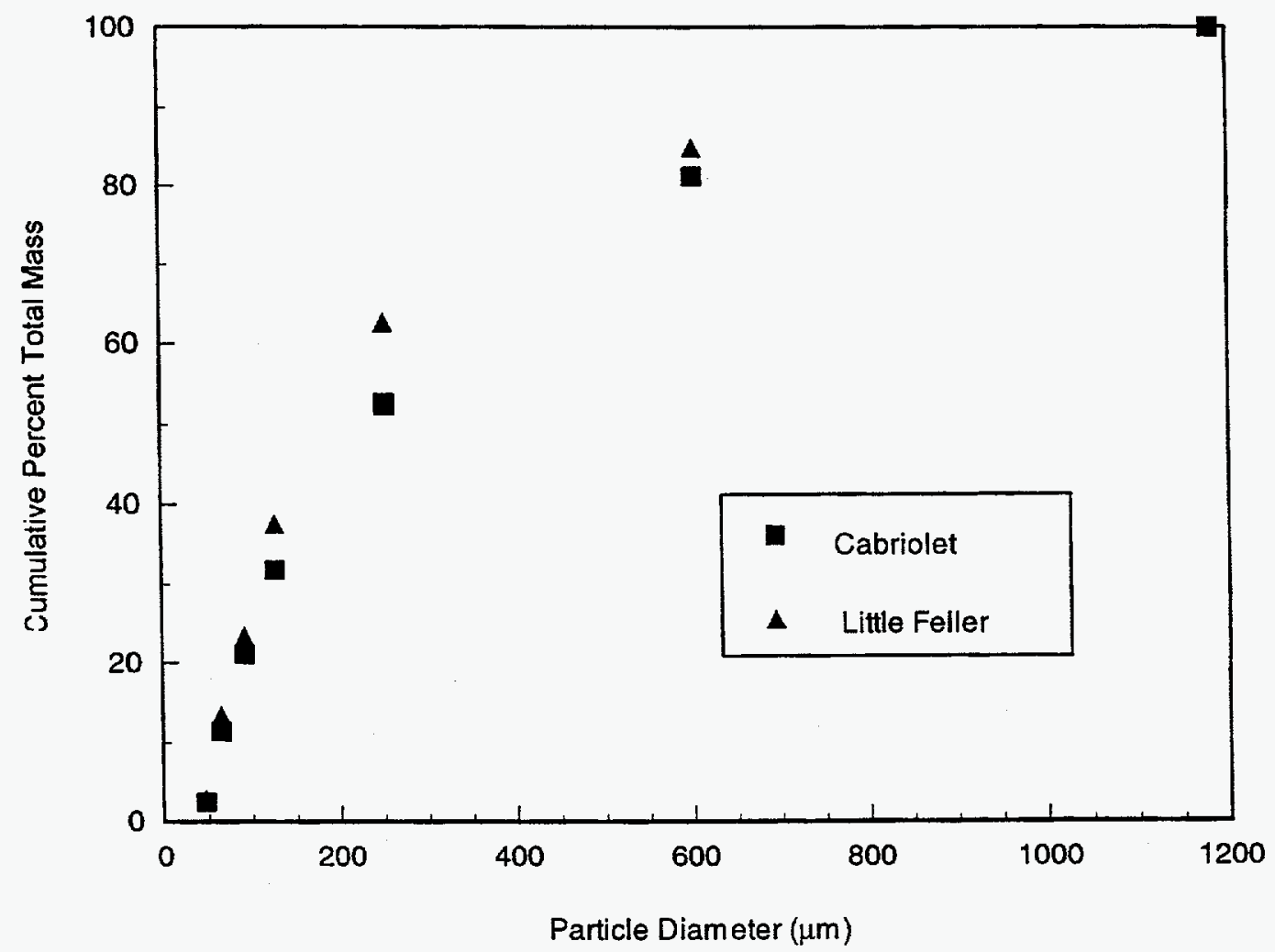

Figure 4. Cumulative percentage mass distribution.

The $\mathrm{pH}$ of the soil solution was measured and the results are shown in Table 2 for both types of soils and for three different particle size fractions: the entire sample (particles smaller than 1,180 $\mu \mathrm{m}$ ), particles between 600 and $1,180 \mu \mathrm{m}$, and particles smaller than $45 \mu \mathrm{m}$. In all cases, equal 
masses of NANOpure ${ }^{T M}$ water and dry soil were used (McLean, 1982). For the coarser size fractions, larger quantities (approximately $15 \mathrm{~g}$ of soil and $15 \mathrm{~mL}$ of water) were used, whereas for the smaller size fractions, smaller quantities were used (approximately $3 \mathrm{~g}$ of soil mixed with $3 \mathrm{~mL}$ of NANOpure $^{T M}$ water). In either case, the solid-to-liquid ratio was one (mass of solid to volume of water).

Several observations can be made by inspection of Table 2 . First, the $\mathrm{pH}$ values measured were within the expected $\mathrm{pH}$ range for natural soils. Second, there are differences between the $\mathrm{pH}$ values for the two soils and the different size fractions. Little Feller soil fractions have higher $\mathrm{pH}$ values overall. These differences can only be related to the mineralogical composition of the two soils and the different size fractions. Typically, soils with a higher percentage of carbonate minerals are expected to have higher solution $\mathrm{pH}$ values than soils with substantial fractions of clay minerals and quartz. Based on this assumption, it appears that Little Feller soil would have a higher carbonate-mineral content than Cabriolet soil. A preliminary x-ray diffraction (XRD) analysis revealed the presence of carbonates (calcite) in both soils.

TABLE 2. SOIL SOLUTION pH.

\begin{tabular}{ccc}
\hline Size Fraction $(\mu \mathrm{m})$ & Cabriolet & Little Feller \\
\hline \hline $\mathrm{d}<1,180$ & 7.80 & 8.89 \\
$600<\mathrm{d}<1,180$ & 8.20 & 8.85 \\
$\mathrm{~d}<45$ & 7.80 & 8.38 \\
\hline
\end{tabular}

It is also interesting to compare the soil solution $\mathrm{pH}$ values for the individual size fractions of the two soils. The $\mathrm{pH}$ values for the composite Cabriolet soil $(\mathrm{d}<1,180 \mu \mathrm{m})$ and the fraction smaller than $45 \mu \mathrm{m}$ were identical ( $\mathrm{pH} 7.80$, Table 2), suggesting that the soil solution $\mathrm{pH}$ is dominated by the solution chemistry of the finer fraction. As expected, the $\mathrm{pH}$ of the finer fraction was lower than the $\mathrm{pH}$ of the intermediate $(600<\mathrm{d}<1,180)$ size fraction $(7.80$ and 8.20 , respectively). The measured $\mathrm{pH}$ value difference ( 7.80 vs. 8.20 ) is significant. Contrary to Cabriolet soil, the $\mathrm{pH}$ of the entire Little Feller soil $(\mathrm{d}<1,180 \mu \mathrm{m})$ was essentially identical to the $\mathrm{pH}$ of the coarser size fraction $(8.89$ and 8.85 , respectively, Table 2) and significantly higher than the $\mathrm{pH}$ of the fine fraction (8.38).

It appears, therefore, that the clay fraction may not be such an important factor in the overall solution of Little Feller soil as it is for Cabriolet soil. In addition, the overall higher $\mathrm{pH}$ values measured for Little Feller soil compared to Cabriolet soil are in agreement with this hypothesis. In both types of soil, however, the presence of a clay size fraction is certain, based on simple sedimentation experiments performed. The presence of common minerals (quartz, calcite, feldspars, and aluminum and iron oxides and hydroxides) in different percentages would tend to change the surface properties of the soil. This is because the surface of different minerals is electrically neutral (neither positively nor negatively charged) at a different $\mathrm{pH}$ value, known as the point of zero charge, $\mathrm{pH}_{\mathrm{PZC}}$. The presence of calcite and oxides and hydroxides of aluminum and iron, with commonly reported $\mathrm{pH}_{\mathrm{PZC}}$ values between 8.5 and 9.0 (Sposito, 1984), would tend to raise 
the soil solution $\mathrm{pH}$. The presence of quartz, with $\mathrm{pH}_{\mathrm{PZC}}$ around 2, would tend to lower the soil solution $\mathrm{pH}$. These assumptions, however, can only be verified through additional careful characterization studies which, because of time and budgetary limitations, could not be performed.

The ionic conductivity of the soil solution for the two soils was also measured to estimate the concentration of dissolved species in equilibrium with the mineral phases present in the soils. The procedure consisted of suspending $25 \mathrm{~g}$ of soil in $100 \mathrm{~mL}$ of NANOpure ${ }^{\mathrm{TM}}$ water, mixing for $15 \mathrm{~min}$, centrifuging at $4,500 \mathrm{rpm}$ for $30 \mathrm{~min}$, followed by measurement of the conductivity of the supernatant. The measured values were 0.21 and $0.54 \mathrm{dS} \mathrm{m}^{-1}$ for Cabriolet and Little Feller soils, respectively. These conductivities indicate normal soils (neither saline nor sodic) (Bohn et al., 1985). Based on a calibration of the conductivity meter with sodium nitrate solutions varying in concentration over several orders of magnitude, these values correspond to an ionic concentration of approximately $1.8 \times 10^{-4}$ and $4.7 \times 10^{-4} \mathrm{M}$ for Cabriolet and Little Feller soils, respectively. These values are within the range of expected dissolved species concentrations.

\section{Materials and Methods}

Sorption experiments were performed in individual $12-\mathrm{mL}$ polypropylene centrifuge tubes. A specific amount of solid was added to the centrifuge tube. The amount of solid varied depending on the final solid concentration desired. A specific amount of $1.0 \mathrm{M} \mathrm{NaNO}_{3}$ (sodium nitrate) was added to achieve the desired final ionic strength of the experiment. A variable amount of either $1.0 \mathrm{M}$ $\mathrm{HNO}_{3}$ (nitric acid) or $0.1 \mathrm{M} \mathrm{NaOH}$ (sodium hydroxide) was added to adjust the $\mathrm{pH}$ to the approximate final $\mathrm{pH}$ value desired. The amounts of acid and base required for $\mathrm{pH}$ adjustment were determined by trial and error.

Typically, a set of four reactors was set up at a time with varying target $\mathrm{pH}$ values. Approximately $30 \mu \mathrm{L}$ of either $1.7 \times 10^{-4}$ or $1.7 \times 10^{-2} \mathrm{M} \mathrm{Co}\left(\mathrm{NO}_{3}\right)_{2} \cdot 6 \mathrm{H}_{2} \mathrm{O}$ (cobalt(II) nitrate hexahydrate) were added to the centrifuge tube to achieve the desired final total Co concentration in the samples, either $10^{-6}$ or $10^{-4} \mathrm{M}$. The necessary quantity of NANOpure ${ }^{\mathrm{TM}}$ water was added to result in a final solution volume of $5 \mathrm{~mL}$. All reagents used were of ACS reagent grade quality or better.

The individual centrifuge tubes were equilibrated for at least one week by end-over-end rotation at $8 \mathrm{rpm}$. Preliminary experiments showed that equilibrium was reached within a few (2-3) days. Following equilibration, the $\mathrm{pH}$ of the suspension was measured using an Orion model 720 $\mathrm{pH}$ meter with an Orion Ross glass combination electrode. The $\mathrm{pH}$ meter was calibrated daily using $\mathrm{pH} 4.00,7.00$, and 10.00 buffers. Solid-solution separation was achieved by centrifugation at 9,000 rpm for 30 min using a Marathon K/R 21 centrifuge and a $1-\mathrm{mL}$ aliquot of the supernatant was removed for metal analysis. The supernatant was acidified with $12 \mu \mathrm{L}$ of concentrated $\mathrm{HNO}_{3}($ Fisher Optima ${ }^{\mathrm{TM}}$ quality) before analysis.

The samples were analyzed using a Varian $600 \mathrm{Z}$ atomic absorption spectrometer with graphite furnace and Zeeman background correction. Duplicates were run for each sample and the results were averaged. In all cases, a concentration mode was used for analysis using a $10^{-6} \mathrm{M}$ Co standard. The fractional uptake (percent adsorbed) for each sample was calculated as: 


$$
\% \text { Adsorbed }=\frac{\mathrm{C}_{0}-\mathrm{C}_{\mathrm{s}}}{\mathrm{C}_{\mathrm{o}}} \times 100
$$

where $C_{o}$ is the total Co concentration added to the sample and $C_{s}$ is the Co concentration remaining in the supernatant.

Several tests were performed to assure the reproducibility of the results. Individual samples were set up with exactly the same additions of soil and reagents to determine the variation of final $\mathrm{pH}$, as a measure of $\mathrm{pH}$ measurement and soil sampling and transferring reproducibility. These tests revealed no significant variations among samples. In addition, tests were performed to determine the reason for the observed $\mathrm{pH}$ drift as a function of time during $\mathrm{pH}$ measurements over a period of time. It was determined that insufficient equilibration was not a reason, because the samples had the same response regardless of equilibration time.

It was speculated that the observed $\mathrm{pH}$ drift was probably caused by a number of factors, including over- or undersaturation with respect to $\mathrm{CO}_{2}$, resulting from precipitation or dissolution of carbonate minerals or from biological activity. Given the limited resources of this project, this interesting behavior could not be investigated further. It was established, however, that measuring the $\mathrm{pH}$ immediately at the end of the equilibration period, followed immediately by solid-solution separation by centrifugation, resulted in reproducible $\mathrm{pH}$ measurements.

\section{RESULTS AND DISCUSSION}

The results of Co sorption on the two NTS soils will be discussed in this section. A parametric study was conducted which included parameters known to influence the sorption behavior of metal ions on mineral surfaces. These parameters include $\mathrm{pH}$, ionic strength, metal ion concentration, solid concentration, and physicochemical characteristics of the mineral surface. A brief explanation of the significance of these parameters, based on the more extensive discussion presented in the section on theoretical background, is given below. The reader is referred to that section and the references listed therein for additional background information.

It is well documented that the fractional uptake of cations by oxides and other minerals is highly pH dependent (Davis and Leckie, 1978; Hayes and Leckie, 1987; Katz and Hayes, 1995; Stumm et al., 1980). A parametric cation sorption study on a natural soil must, therefore, include experiments performed as a function of $\mathrm{pH}$, because oxides and oxide coatings often determine the sorption characteristics of natural soils. Cation sorption on clay minerals may or may not be $\mathrm{pH}$ dependent. Sorption on non-expanding, 1:1 clays (e.g., kaolinite) with primarily surface-hydroxyl sorption sites, is expected to be highly pH dependent (O'Day et al., 1994a; O'Day et al., 1994b), whereas sorption on smectites (2:1 expanding clays) may or may not be $\mathrm{pH}$ dependent, depending on other geochemical conditions (Papelis and Hayes, 1996). Because the exact mineralogical composition of the soils was not known, $\mathrm{pH}$ was assumed to be an important experimental parameter. It was attempted to adjust the $\mathrm{pH}$ between 4 and 9, i.e., values within a $\mathrm{pH}$ range likely to be encountered in nature, by addition of acid or base. The resulting final $\mathrm{pH}$ was not always within the target range, 
as can be seen by inspection of the results, because of the somewhat unpredictable response of the complex mineral matrix to acid or base addition.

The metal ion and solid concentrations can also have a dramatic influence on cation partitioning at the mineral-water interface, because they determine the ratio of sorbate ions to the total number of sorbent sites. It has been shown in numerous studies that the affinity of an ion for the surface decreases with increasing surface coverage. To cover quite a wide range of adsorbate-adsorbent ratios, experiments were conducted with two solid concentrations (solid mass per volume of solution), 20 and $100 \mathrm{~g} / \mathrm{L}$, and Co concentrations $10^{-6}$ and $10^{-4} \mathrm{M}$. In addition, because the relative abundance of minerals (and therefore site types) was expected to be different in different size fractions, experiments were conducted with both the entire sample (particles smaller than 1,180 $\mu \mathrm{m}$ ) and the smaller size fraction (particles smaller than $45 \mu \mathrm{m}$ ) where a larger percentage of clay particles was expected.

The importance of ionic-strength effects on anion and cation sorption onto oxide surfaces depends on the nature of the anion or cation (Hayes and Leckie, 1987; Hayes et al., 1988). As stated in the theoretical background section, sorption of strongly binding ions is not greatly affected by variations in ionic strength, whereas sorption of weakly binding ions may be greatly affected. Ionic strength effects of ion sorption on clays are more complex and depend on the types of sorption sites present (Papelis and Hayes, 1996).

Sorption of Co on oxides is thought to be ionic-strength independent (Katz and Hayes, 1995), but sorption of Co on smectites may be ionic-strength dependent (Papelis and Hayes, 1996). Because the natural soils used in this study most likely include different types of minerals, such as oxides, carbonates, and clay minerals, the effects of ionic strength on Co sorption were studied by conducting experiments in 0.1 and $0.01 \mathrm{M} \mathrm{NaNO}_{3}$. Previous experiments with montmorillonite, at lower solid concentrations, have shown that the increase of ionic strength from 0.01 to $0.1 \mathrm{M}$ is sufficient to force Co from sorption sites in the interlayer spacings to the external surface-hydroxyl sites (Papelis and Hayes, 1996). Results relevant to the entire study will be discussed first, followed by discussion of specific experiments with Cabriolet and Little Feller soils, respectively. Finally, results from experiments with the two types of soils will be compared.

As stated above, experiments were conducted with two solid concentrations, 20 and $100 \mathrm{~g} / \mathrm{L}$, to investigate the effects of surface site coverage on Co uptake. These solid concentrations were arbitrarily selected based on estimated soil characteristics (including mineral composition and specific surface area) to result in a range of low to high surface coverages. Such estimates are particularly difficult in the absence of prior experimental experience with a given system. Current experience suggests that solid concentration of $20 \mathrm{~g} / \mathrm{L}$ provides adequate surface area to conduct a parametric study using the experimental parameters tested in this study (pH, metal concentration, particle size distribution, and soil type). The higher solid concentration $(100 \mathrm{~g} / \mathrm{L})$ apparently resulted in low surface coverages and essentially quantitative (100\%) removal of Co from solution. In addition, the equilibrium $\mathrm{pH}$ in all experiments at the higher solid concentration was in a relatively narrow $\mathrm{pH}$ range (between 6 and 8 ) and, therefore, the conditions for these experiments were not 
different enough to allow distinction between sorption at different sorption sites. Only experiments at the lower solid concentration $(20 \mathrm{~g} / \mathrm{L})$ will therefore be discussed below.

Ionic strength effects on Co sorption on Cabriolet soil are shown in Figure 5. Results from experiments with total Co concentration $10^{-4} \mathrm{M}$ (using the smaller than $45 \mu \mathrm{m}$ soil fraction) and $10^{-6}$ M (using the entire soil sample, particles smaller than 1,180 $\mu \mathrm{m}$ ) are shown. For both of these conditions, experiments were performed at 0.1 and $0.01 \mathrm{M}$ ionic strength. For all four data sets shown in Figure 5, fractional Co uptake is shown for both low pH (below 4) and neutral pH (6 to 8) samples.

The ionic strength dependence data at the higher Co concentration $\left(10^{-4} \mathrm{M}\right)$ and smaller particle size fraction $(45 \mu \mathrm{m})$ reveal dramatic differences in sorption behavior at the two ionic strengths. At the low ionic strength $(0.01 \mathrm{M})$, sorption appears to be essentially $\mathrm{pH}$ independent, with fractional uptake practically $100 \%$ for both low and high pH samples. At the higher ionic strength (0.1 M), however, sorption appears to be strongly $\mathrm{pH}$ dependent, with fractional Co uptake increasing from approximately $30 \%$ at low $\mathrm{pH}$ to essentially $100 \%$ at neutral $\mathrm{pH}$.

These results are consistent with Co sorption on both interlayer, ion-exchange sites of smectite clays and amphoteric, surface hydroxyl sites of oxides or aluminosilicate minerals. At low ionic strength, Co can successfully compete with background electrolyte cations and sorb on interlayer,

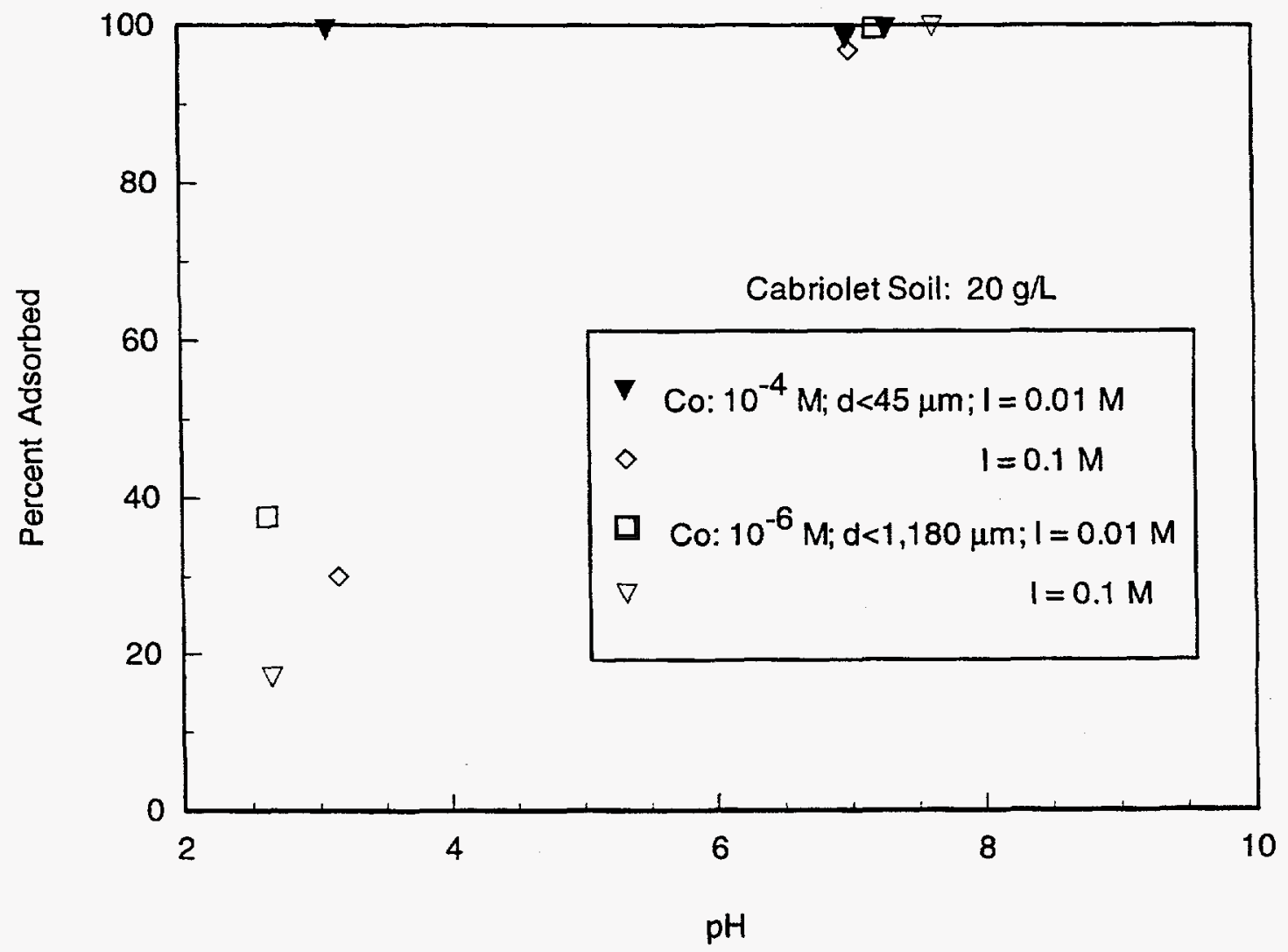

Figure 5. Co sorption on Cabriolet soil as a function of ionic strength. 
ion-exchange sites. Because the structural charge of these sites is $\mathrm{pH}$ independent, sorption on these sites is also $\mathrm{pH}$ independent. Assuming that Co sorption is not limited by the availability of ion-exchange sites in the interlayer basal planes of clay minerals, essentially quantitative removal of the trace-metal cation is expected. Given the high Co concentration used in this experiment, these results suggest a relatively high concentration of smectite clay minerals in this fraction of the Cabriolet soil. This is not surprising, given that this fraction is comprised of particles smaller than $45 \mu \mathrm{m}$.

At the higher ionic strength, sodium (Na) can apparently, at least partly, displace Co from the interlayer spacings, thereby limiting Co sorption to external, amphoteric surface-hydroxyl sites of smectite minerals or oxides. The $\mathrm{pH}$-dependent sorption of $\mathrm{Co}$ under these conditions, shown in Figure 5, is consistent with the well-documented, $\mathrm{pH}$-dependent sorption of cations on oxide surfaces (see the section on theoretical background for an introduction and background to metal ion sorption on oxide and clay minerals). At low $\mathrm{pH}$, very little fractional uptake of even strongly binding cations is expected, whereas at higher $\mathrm{pH}$, in the absence of site limitations, nearly quantitative sorption of cations is expected and is actually observed in Figure 5.

It is reasonable to assume that sufficient surface-hydroxyl sites are available at this solid concentration for quantitative removal of $10^{-4} \mathrm{M} \mathrm{Co}$. Sorption on ion-exchange sites, however, under these conditions cannot be ruled out either. Limited Co uptake at low $\mathrm{pH}$ may in fact be evidence of some limited sorption on ion-exchange sites, even at the higher ionic strength. It would be impossible to distinguish between sorption on surface-hydroxyl and permanent-charge, ion-exchange sites without a detailed mineralogical characterization of the soil and advanced spectroscopic techniques, such as X-ray Absorption Spectroscopy (XAS). XAS was successfully used in the past to distinguish between Co sorption on external and interlayer sorption sites of montmorillonite (Papelis and Hayes, 1996).

The ionic-strength-dependence results of $10^{-6} \mathrm{M}$ Co sorption on the entire Cabriolet soil sample (smaller than $1,180 \mu \mathrm{m}$ fraction) are also shown in Figure 5. The data suggest $\mathrm{pH}$-dependent sorption behavior for both high and low ionic strength. These data are, therefore, substantially different from the fine particle size fraction results. At neutral $\mathrm{pH}$, fractional uptake is essentially $100 \%$, as in the fine particle size case. At low pH, however, the difference between the high and low ionic strength results is substantially less pronounced compared to the fine-grain-size results, although fractional uptake is still reduced at the higher ionic strength.

These results can be explained based on the mineralogical composition of the two size fractions. Smectites and other clay minerals are expected to comprise a larger percentage of the soil in the smaller than $45 \mu \mathrm{m}$ fraction compared to the entire soil fraction (all particles smaller than $1,180 \mu \mathrm{m})$. The results are consistent with this observation. In the fine-particle-size fraction, the data shown are consistent with ionic strength dependence data in experiments with pure montmorillonite, i.e., sorption is greatly ionic-strength dependent at low $\mathrm{pH}$ values. In the coarser size fraction, however, the results are substantially less ionic-strength dependent, suggesting that sorption is controlled by abundance of surface-hydroxyl sites, as expected. Significant metal ion sorption even 
at $\mathrm{pH}$ below 3 (approximately 20 and $40 \%$ for the high and low ionic strength, respectively) is indicative of sorption at ion-exchange sites, which are undoubtedly present.

The results shown in Figure 5, therefore, represent a combination of ionic strength and particle-size effects and have significant implications for the mobility of Co in soils at the NTS. First, they suggest that Co movement in NTS soils would be significantly retarded, as long as the solution $\mathrm{pH}$ is higher than 6 (e.g., neutral), because nearly quantitative (100\%) removal is observed under these conditions. The measured soil solution $\mathrm{pH}$ for both types of soils and for all size fractions was actually above 7 , as can be seen from Table 2 . It is important to note that nearly $100 \%$ sorption was observed even at the higher metal concentration, $10^{-4} \mathrm{M}$, and at the lower solid concentration, $20 \mathrm{~g} / \mathrm{L}$. Both of these assumptions are conservative. It is rather unlikely that concentrations of radionuclides or trace metals so high would be encountered anywhere on the NTS. In addition, batch solid concentrations on the order of $20 \mathrm{~g} / \mathrm{L}$ are fairly low and therefore this solid-to-liquid ratio would be equivalent to a significant number of pore volumes required for Co transport in a column experiment. Finally, these results suggest that metal ion fate and transport in these soils may be controlled by sorption on both clay minerals and oxides, carbonates, and oxide coatings.

The effect of metal ion concentration on Co sorption onto Cabriolet soil (soil fraction smaller than $1,180 \mu \mathrm{m}$ ) is shown in Figure 6, at the higher ionic strength, $0.1 \mathrm{M}$. Data are shown at low and neutral $\mathrm{pH}$ for both Co concentrations used, $10^{-6}$ and $10^{-4} \mathrm{M}$.

As can be seen from Figure 6, the data indicate strong $\mathrm{pH}$ dependence of sorption, a result consistent with the previous discussion of ionic strength effects and the high ionic strength used in these experiments.

Inspection of the data in Figure 6 indicates rather small differences in Co uptake at the two concentrations. Although $\mathrm{pH}$-dependent sorption is an indication of metal ion sorption on amphoteric, surface-hydroxyl sites, it would be an oversimplification to assume that sorption on such sites can entirely account for the observed uptake behavior. First, it is highly unlikely that up to $20 \%$ of $10^{-4} \mathrm{M}$ Co would sorb on surface-hydroxyl sites at $\mathrm{pH}$ values lower than 3 , as the data suggest. Second, the data are inconsistent with expected trends of metal ion sorption, as a function of concentration, on oxides. Higher total metal ion concentrations lead to increased coverage of surface sites and, therefore, sorption on energetically less favored sites. Occupation of energetically less favored sites is demonstrated by a reduction of the fractional uptake (in terms of percent metal sorbed) with increased total metal concentration, although the total metal sorbed may increase with increasing total metal concentration. The data in Figure 6 suggest, if anything, higher fractional uptake at the higher Co concentration, although the small difference could easily lie within the experimental margin of error.

It is more likely that the observed data reflect a combination of sorption on both surface-hydroxyl and ion-exchange sites. Presence of smectite clays, and therefore ion-exchange sites, is supported by sorption data with the smaller size fraction (smaller than $45 \mu \mathrm{m}$ ), although the relative abundance of ion-exchange sites in the coarser size fraction (smaller than $1,180 \mu \mathrm{m}$ ) is expected to be lower. Sorption on ion-exchange sites can account for the observed cation sorption 


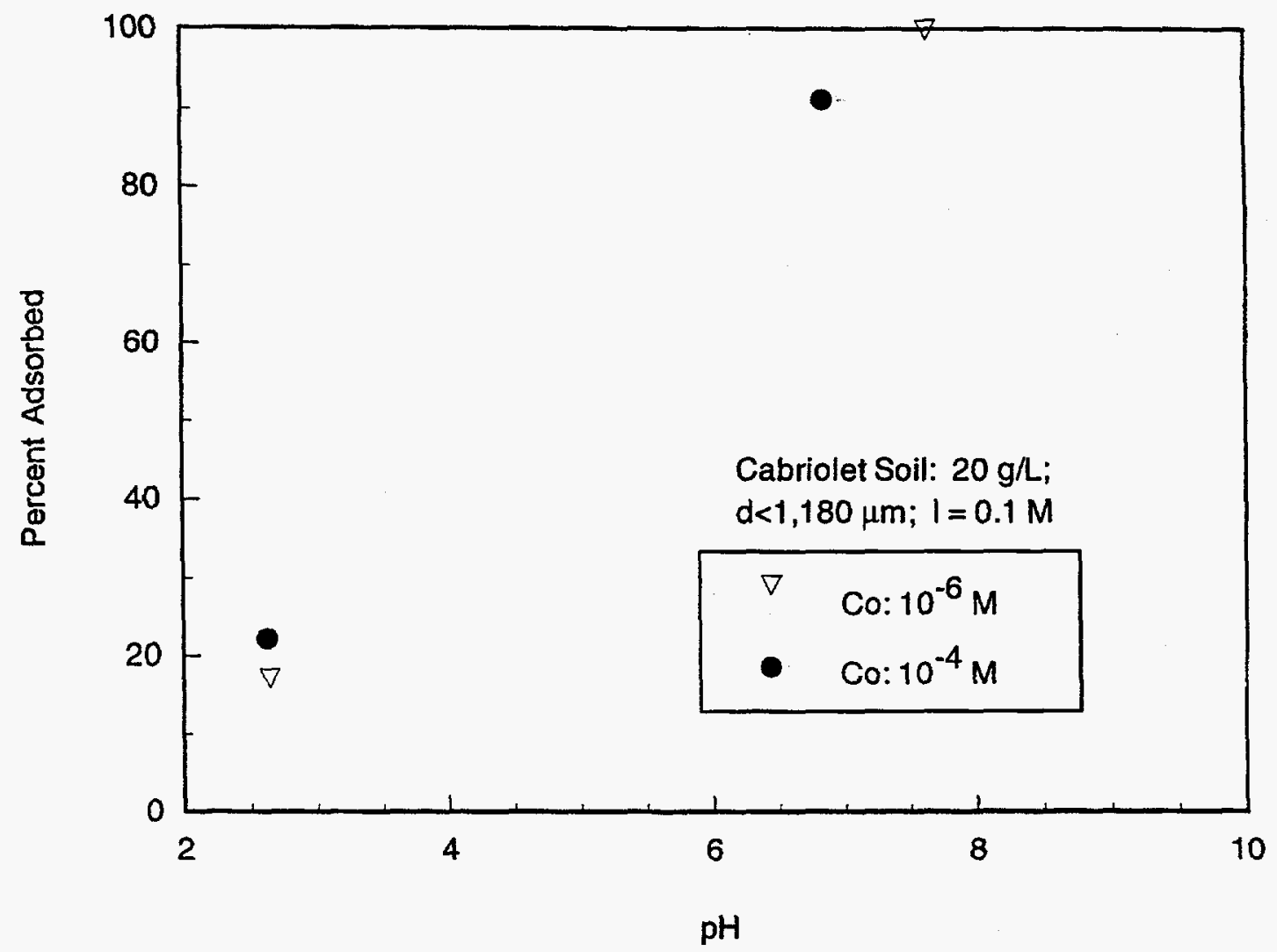

Figure 6. Co sorption on Cabriolet soil as a function of metal concentration.

even at low $\mathrm{pH}$ and for the relatively low concentration dependence of Co sorption. At higher $\mathrm{pH}$, both surface-hydroxyl and ion-exchange sites are expected to contribute to Co sorption and to account for essentially complete removal of the metal cation from solution. As stated earlier, however, confirmation of this hypothesis would require additional spectroscopic experiments. In summary, all experimental data obtained with $20 \mathrm{~g} / \mathrm{L}$ of Cabriolet soil are shown in Figure 7 .

Sorption of Co on Little Feller soil will be discussed next. As already stated, all experiments at the high solid concentration $(100 \mathrm{~g} / \mathrm{L})$ were conducted at neutral $\mathrm{pH}$ and resulted in complete removal of Co from solution. These experiments will not be discussed further. Unfortunately, because of budgetary constraints and analytical difficulties, it was not possible to obtain a complete set of data for all experimental conditions at both neutral and low $\mathrm{pH}$ values. Low $\mathrm{pH}$ data (below 4) were only obtained for the entire soil fraction smaller than $1,180 \mu \mathrm{m}$ and high ionic strength $(0.1$ $\mathrm{M}$ ), at both Co concentrations, $10^{-4}$ and $10^{-6} \mathrm{M}$. It is, therefore, impossible to compare all aspects of the results obtained with the two soils. Several useful comparisons, however, can be made.

Sorption of $\mathrm{Co}$ on the entire Little Feller soil and at high ionic strength is shown as a function of Co concentration in Figure 8. Several observations can be made. First, Co sorption is definitely $\mathrm{pH}$ dependent, as expected for metal ion uptake controlled by sorption on oxides and carbonate minerals. At the high ionic strength of these experiments, $\mathrm{Na}$ is expected to displace $\mathrm{Co}$, at least 


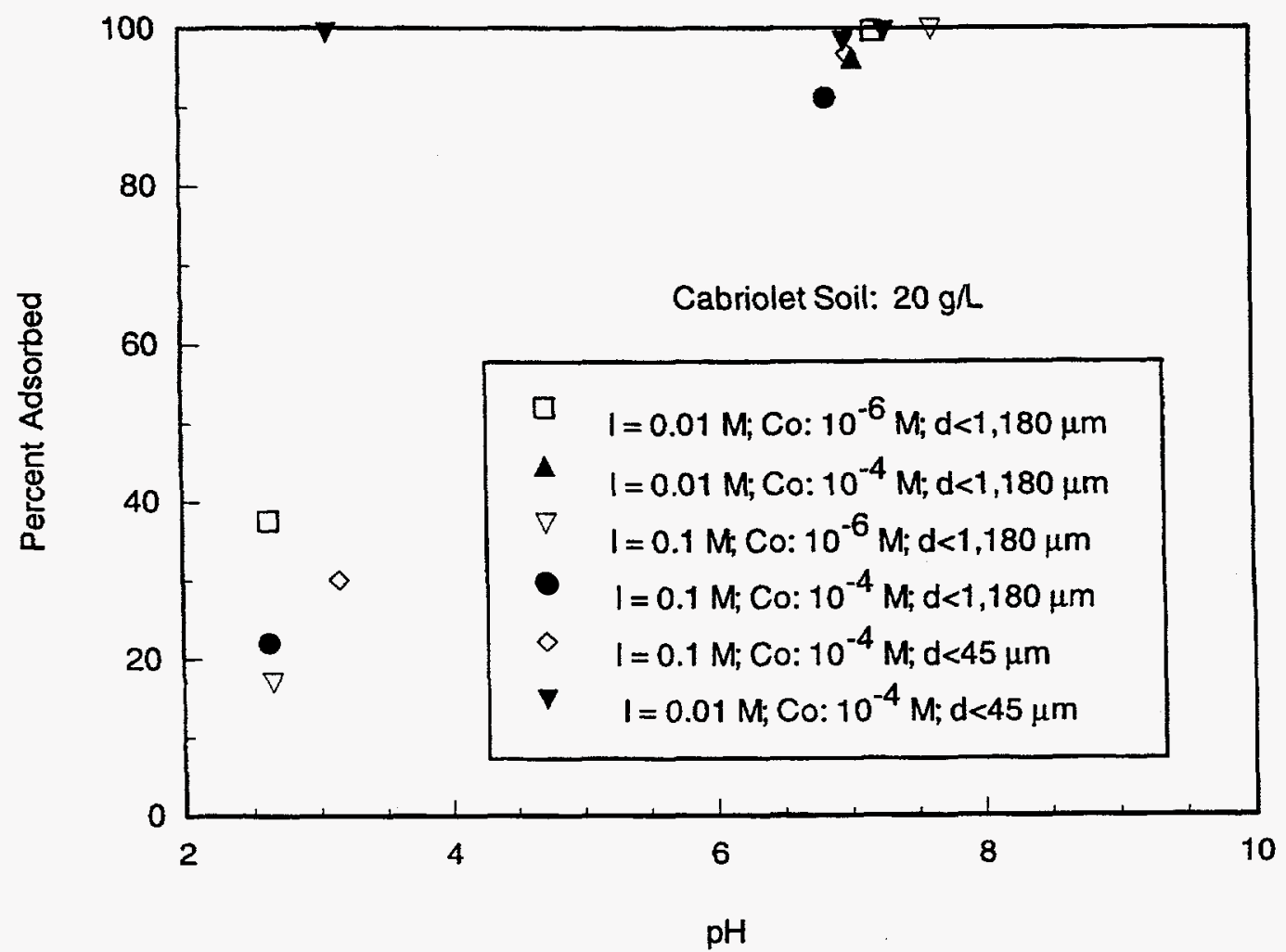

Figure 7. Summary of Co sorption results on $20 \mathrm{~g} / \mathrm{L}$ of Cabriolet soil.

partly, from ion-exchange sites. Because metal ion sorption on surface-hydroxyl sites is insignificant at low $\mathrm{pH}$, overall Co fractional uptake is low under conditions of high ionic strength and low $\mathrm{pH}$. The limited Co sorption shown in Figure 8 at low $\mathrm{pH}$ can be most likely attributed to sorption on ion-exchange sites. These sites definitely exist to some appreciable extent in the entire soil fraction.

The data shown in Figure 8 follow expected trends for metal ion sorption as a function of concentration, i.e., decreasing fractional uptake with increasing total metal concentration. This trend is evident from the position of the adsorption edge for the two metal concentrations. Despite the limited data, it should be clear that the Co sorption edge is shifted to higher $\mathrm{pH}$ values at the higher Co concentration. Although pH-dependent metal ion sorption clearly suggests sorption on amphoteric surface-hydroxyl sites, it is unlikely that this type of site alone could account entirely for the observed fractional uptake under these conditions. The observed sorption behavior is most likely a combination of sorption on both surface-hydroxyl and ion-exchange sites. This hypothesis is supported by the relatively high (50\%) sorption of $10^{-6} \mathrm{M} \mathrm{Co}$ at $\mathrm{pH}$ below 4 . With increasing $\mathrm{pH}$, the contribution of sorption on amphoteric sites increases as well and accounts for the quantitative removal of $\mathrm{Co}$ at $\mathrm{pH}$ above 8 , even at the high Co concentration.

It is also worth noting that the data set at this ionic strength $(0.1 \mathrm{M})$ and at the high Co concentration $\left(10^{-4} \mathrm{M}\right)$ is the only experimental data set where fractional uptake above $\mathrm{pH} 6$ is less 


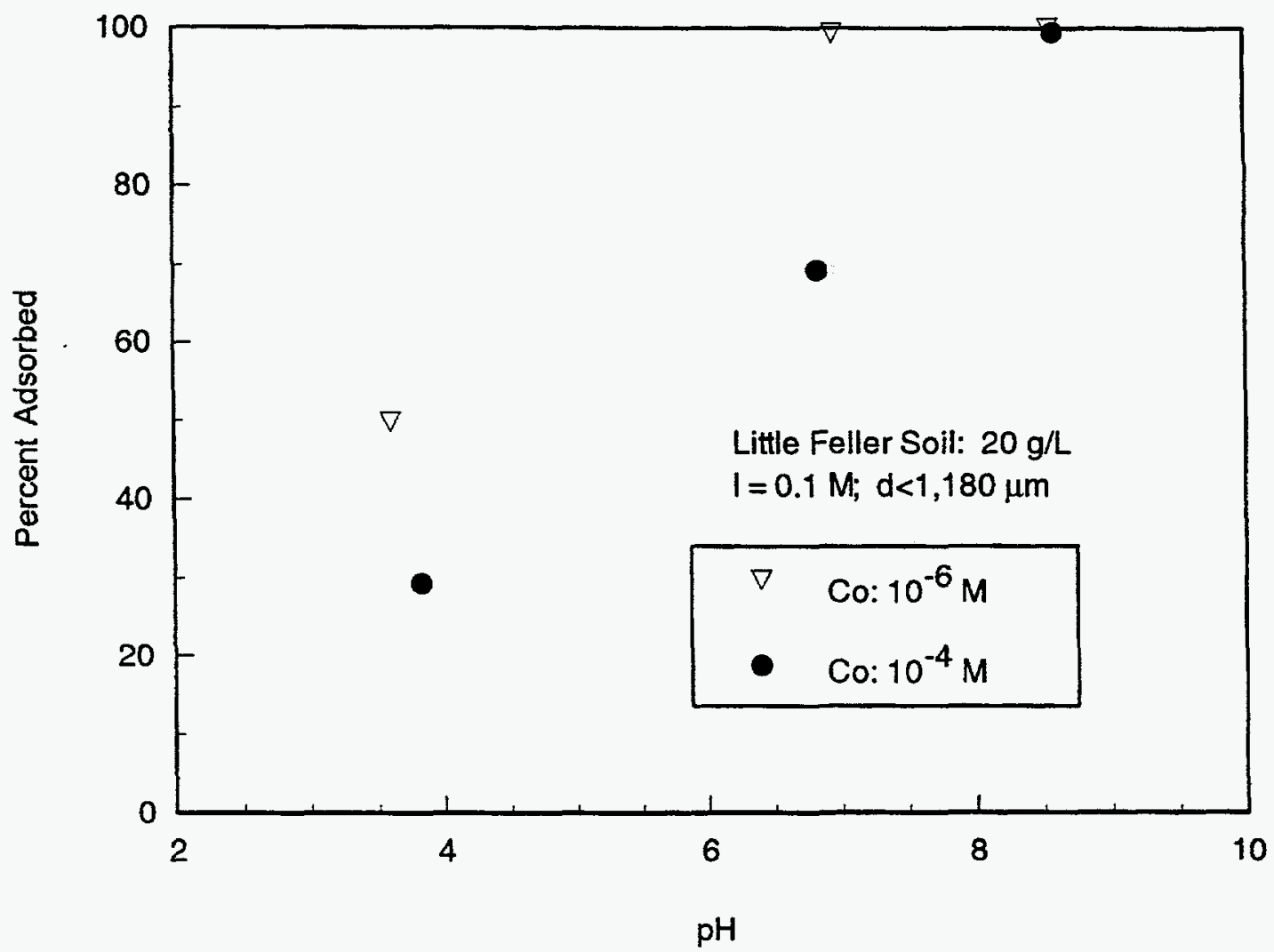

Figure 8. Co sorption on Little Feller soil as a function of metal concentration.

than $90 \%$. This data set is therefore useful in determining the sorption capacity of this soil matrix and has significant implications for the mobility of Co in these soils. All experiments with Little Feller soil, except for the ones discussed in Figure 8, resulted in equilibrium pH values at or above 7 and fractional uptake at least $90 \%$. All data with $20 \mathrm{~g} / \mathrm{L}$ Little Feller soil are summarized in Figure 9.

Because the experimental conditions were not identical for the two types of soils, it is not possible to fully compare the experimental results between the two soil matrices. The limited data on which such a comparison can be based, however, suggest that Co sorption and mobility on these two soils is not substantially different. This can be seen in Figure 10, where Co sorption as a function of concentration is shown for experiments conducted with the entire soil fraction of both soils, at ionic strength $0.01 \mathrm{M}$.

As expected, Co sorption in $0.1 \mathrm{M}$ ionic strength is clearly $\mathrm{pH}$ dependent. The data shown in Figure 10, for both concentrations and for both soil types, are in agreement with this hypothesis. At low $\mathrm{pH}$ fractional uptake is reduced, while at neutral or higher $\mathrm{pH}$ fractional uptake approaches $100 \%$. As stated earlier, such behavior is consistent with, at least partial, displacement of Co from ion-exchange sites of smectite clays and sorption on external, surface-hydroxyl sites of clay minerals or oxide minerals and coatings. The relatively high fractional uptake of $\mathrm{Co}$ at low $\mathrm{pH}$ values (lower 


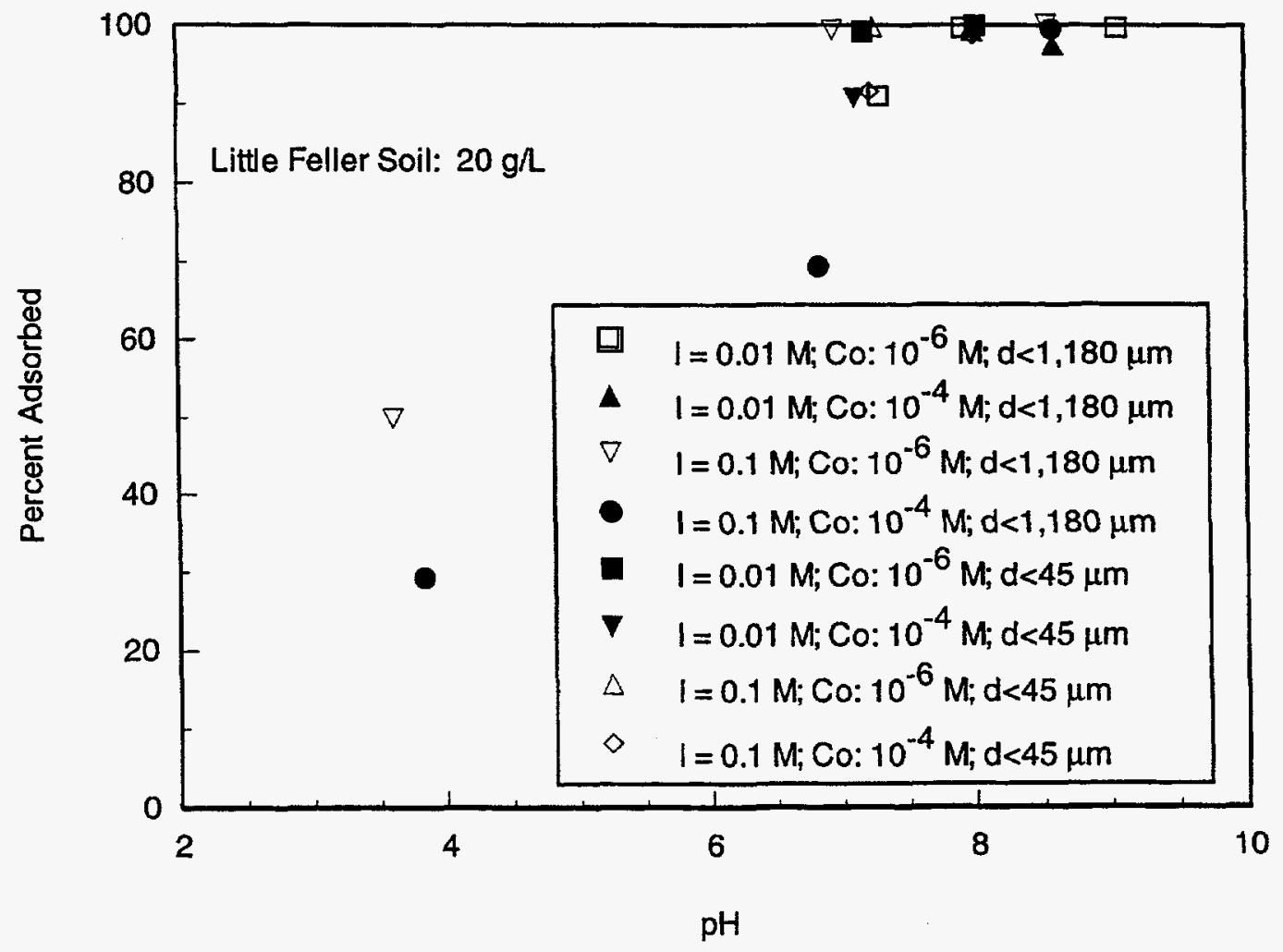

Figure 9. Summary of Co sorption results on $20 \mathrm{~g} / \mathrm{L}$ of Little Feller soil.

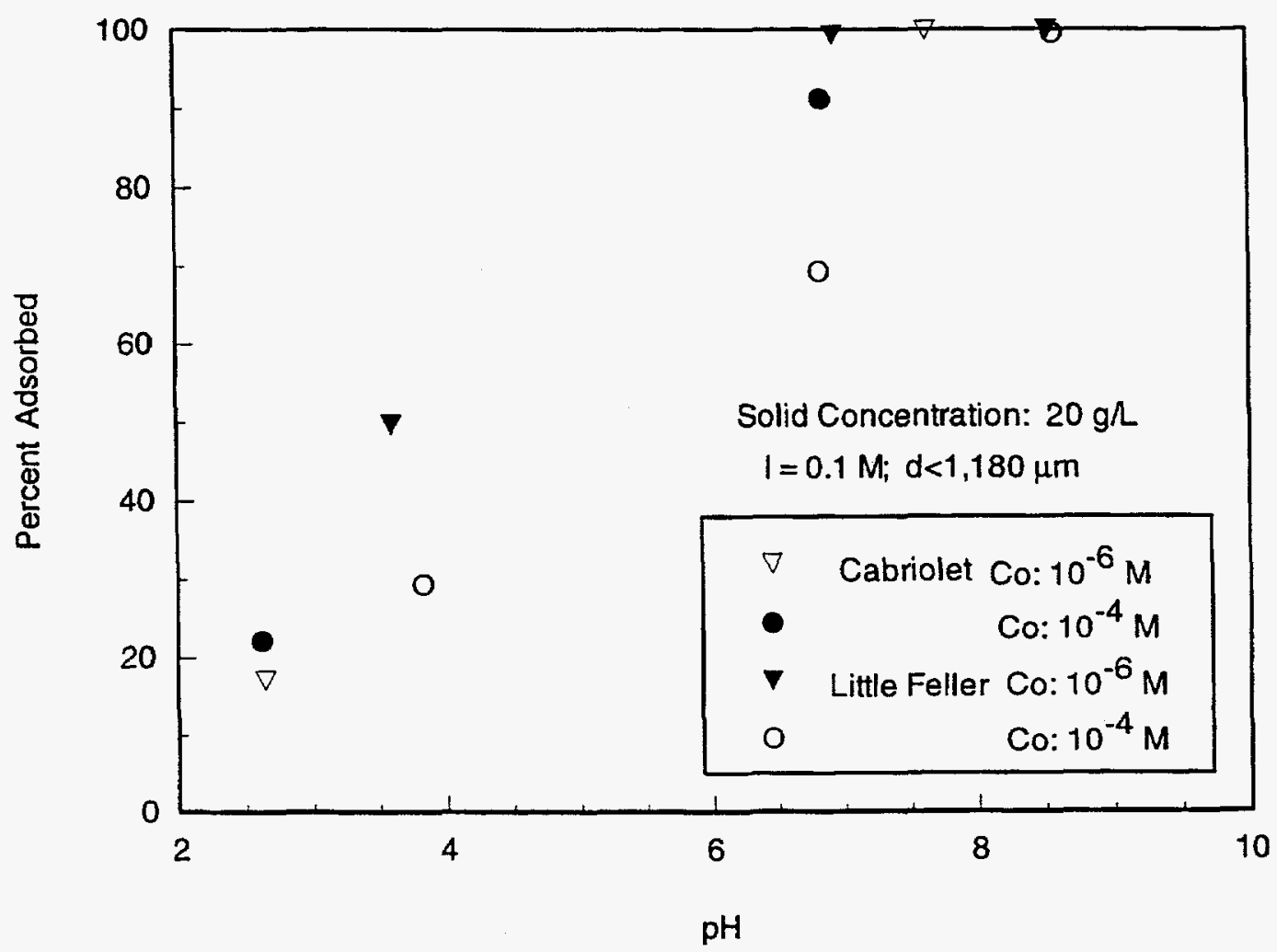

Figure 10. Comparison of Cabriolet and Little Feller Co sorption data; $\mathrm{I}=0.1 \mathrm{M}, \mathrm{d}<1,180 \mu \mathrm{m}$. 
than $\mathrm{pH}$ 4) is an indication of at least partial sorption on ion-exchange sites of clay minerals under these conditions. This statement is supported by the fact that under these experimental conditions and at low $\mathrm{pH}$, the contribution of carbonates and oxides to metal ion sorption is expected to be relatively small. The major source of metal ion sorption sites below $\mathrm{pH} 4$ is expected to be clay minerals.

Comparison of fractional uptake for both concentrations and for both soil types, shown in Figure 10, is in agreement with the expected trend of decreased fractional uptake with increasing total metal concentration. At neutral or higher $\mathrm{pH}$ values, almost quantitative Co removal is observed for both concentrations and for both soils. Comparison of results obtained with the two soils, for the same conditions, suggests rather small differences between the two soil types (Figure 10). In addition to the data shown in Figure 10, other data at neutral or higher $\mathrm{pH}$ are essentially indistinguishable for the two soil types (essentially quantitative removal of Co is observed), as can be seen in Figure 7 and Figure 9.

These results have significant implications for the mobility of Co in Cabriolet and Little Feller soils. Co appears to be highly immobile under most conditions expected in a natural environment. Specifically, at soil pH values common in these soils (around 8), Co is expected to be quantitatively bound to the soil under all conditions tested, including relatively high ionic strengths and Co concentrations. At lower $\mathrm{pH}$ values, Co mobility appears to increase only at high ionic strengths. These conclusions are valid even at relatively low solid concentrations. Although preliminary, these data suggest that Co is severely retarded under most environmental conditions, and therefore an attempt to displace Co from a contaminated surface layer would require substantial water volumes. These conclusions will be presented in greater detail in the following section, along with recommendations for additional investigations.

\section{SUMMARY, CONCLUSIONS, AND RECOMMENDATIONS}

To assess the mobility of Co, a radionuclide commonly found in soils contaminated as a result of nuclear testing, sorption experiments were conducted with soils from the Cabriolet and Little Feller event sites of the NTS. Such studies are necessary to evaluate the potential of contaminant migration on the NTS and to select an appropriate remediation technology. The studies included a preliminary, limited soil characterization and a parametric sorption study.

The soil characterization included separation by particle size using an automated Rotap ${ }^{\mathrm{TM}}$ sieving screen system. The soil fraction larger than $1,180 \mu \mathrm{m}$ was discarded. The particle size distribution for the two soils was similar. Additional soil characterization included soil solution $\mathrm{pH}$ and conductivity measurements. Ionic conductivities were similar for the two soils and indicated normal (neither saline nor sodic) soils. The $\mathrm{pH}$ values measured were also within expected values for natural arid soils but were different for the two soils. Little Feller soil $\mathrm{pH}$ was higher than Cabriolet soil $\mathrm{pH}$. The differences were probably caused by differences in the mineral composition of the two soils. The differences in solution $\mathrm{pH}$ among size fractions, for any given soil type, were probably caused by differences in the relative abundance of $\mathrm{pH}$-determining minerals. The organic fraction content of the two soils also appeared to be different. 
Sorption experiments were conducted with both soils using the entire soil fraction (all particles smaller than $1,180 \mu \mathrm{m}$ ) and the fraction smaller than $45 \mu \mathrm{m}$. Other experimental parameters included solid and Co concentration, $\mathrm{pH}$, and ionic strength. Solid concentration was either 20 or $100 \mathrm{~g} / \mathrm{L}$, Co concentration was either $10^{-6}$ or $10^{-4} \mathrm{M}$, the equilibrium $\mathrm{pH}$ varied between approximately 3 and 9 , and the ionic strength was either 0.1 or $0.01 \mathrm{M}$.

Co sorption on Cabriolet and Little Feller soils appears to be dependent on specific experimental conditions, including $\mathrm{pH}$, total solid concentration, total metal concentration, particle size distribution, and ionic strength. This sorption dependence is related to the relative importance and abundance of different types of sites available for sorption. The fractional coverage of individual types of sites by the metal cation also affects $C$ fractional uptake. The results reported here suggest that at least two types of sites exist in these soils and contribute to the observed sorption behavior: ion-exchange (permanent-charge) sites on smectite clay minerals and amphoteric (surfacehydroxyl) sites on oxides and oxide coatings, as well as on the edges of clay particles. At low ionic strength, Co can sorb on interlayer, ion-exchange sites of clay minerals, while at high ionic strength Co is increasingly excluded from permanent-charge, ion-exchange sites and sorbs on amphoteric, surface-hydroxyl sites.

Because the overall sorption behavior is a function of the relative abundance of these sites, Co uptake by the different particle size fractions of the soils is substantially different. In the smaller particle size fraction (particles smaller than $45 \mu \mathrm{m}$ ) sorption is controlled by clay minerals, a fact reflected in the relatively high ionic strength dependence of sorption. In the coarser size fraction (all particles smaller than $1,180 \mu \mathrm{m}$ ), the relative abundance of ion-exchange sites is lower and the observed ionic strength dependence of sorption is also reduced.

It should be noted that even the most carefully designed ionic strength dependence experiments cannot guarantee exclusive cation sorption on either ion-exchange or surface-hydroxyl sites. Given the complexity of natural soils, it is most likely that the results reported here are a combination of sorption on at least these two types of sites. It is clear, however, that ionic strength may influence the relative binding affinity of cations for these soils. It should also be noted that ionic-strength effects were only obvious at the higher ionic strength used in this study $(0.1 \mathrm{M})$. This concentration is relatively high and not likely to be found in most natural environments, except in saline lacustrine environments. It should also be considered that the results reported here are a function of the solid concentration used.

The reported results indicate that $\mathrm{Co}$ is quantitatively sorbed on these soils (at least $90 \%$ sorbed), under all conditions, when the $\mathrm{pH}$ is above 7 and the solid concentration is at least $20 \mathrm{~g} / \mathrm{L}$. Given that the soil solution $\mathrm{pH}$ of these soils is approximately 8, Co is expected to bind strongly on these NTS soils under commonly expected environmental conditions. Results at higher solid concentrations $(100 \mathrm{~g} / \mathrm{L})$ agree with these conclusions, at least at neutral $\mathrm{pH}$ values and above. In addition, no substantial differences were observed between the two different types of soils, although the preliminary soil characterization indicates that certain differences do exist between the two soil types. 
Based on the experiments reported, Co appears to bind strongly on both Cabriolet and Little Feller soils. This has significant implications for the mobility of Co in these soils and for the remediation of contaminated areas. It appears that migration of Co would be severely retarded under most but extreme conditions. Such conditions might include acidic $\mathrm{pH}$ (approximately 4 or below) and high ionic strength soil solutions (approximately $0.1 \mathrm{M}$ ). Similarly, an attempt to displace Co from the upper layers of the soil profile might require unrealistically large quantities of water, given that the results reported here were obtained at relatively low solid concentrations $(20 \mathrm{~g} / \mathrm{L})$.

The results from this study suggest that metal-ion binding on Cabriolet and Little Feller soils may be controlled by sorption on either permanent-charge, ion-exchange sites of clay minerals or on amphoteric surface-hydroxyl edge sites of the same minerals and oxides, depending on solution conditions. Sorption on interlayer, ion-exchange sites of clay minerals may be responsible for the retardation of a variety of cations and radionuclides, because a number of cations and radionuclides are expected to exchange on these sites in a rather non-specific manner. Sorption on surface-hydroxyl sites, however, is a much stronger function of specific interactions between the sorbing cation and surface sites. The experiments with Co performed in this study are representative of the behavior of cations binding strongly on amphoteric surface-hydroxyl surfaces. It is likely that cations and radionuclides which form weaker complexes with surface hydroxyls will exhibit markedly different behavior. Verification of this hypothesis, however, would require additional experiments.

These additional studies should include experiments with additional cations and anions. Additional cations might include cations that are thought to form weaker complexes on oxide surfaces, such as strontium and cesium. In addition, experiments with weakly and strongly binding anionic contaminants should be conducted to evaluate the mobility and remediation potential of these contaminants. These anions could include selenite, a strongly binding anion, and selenate, a weakly binding anion of the element selenium, which is of significant environmental concern and is frequently found in radioactive waste. Experiments with chromate, an additional anion of environmental concern, would also be useful.

The soil characterization should be completed by including measurements of surface area and porosity, as a function of particle size fraction. In addition, $\mathrm{x}$-ray diffraction analysis on individual size fractions should be performed to characterize the samples with respect to mineralogical composition. Additional characterization should include determination of iron and manganese oxides and organic fraction of the soils. These soil components may be particularly important for the observed sorption behavior in these soils.

Finally, it should be kept in mind that the prediction of Co mobility in these soils and the potential for mobility of other cations and radionuclides, as expressed in this report, are based only on batch sorption experiments and equilibrium interactions between one metal cation and the inorganic and organic constituents of these soils. Transport of contaminants, however, is often controlled by the movement of clay-size-fraction particles and colloids with which contaminants are frequently associated. The next step in the evaluation of migration potential of these contaminants 
in the affected areas should therefore include carefully designed column studies. The scope of these studies would be to realistically simulate contaminant migration by coupling solute-mineral surface interactions with particle breakthrough curves.

\section{REFERENCES}

Bohn, H.L., B.L. McNeal and G.A. O’Connor, 1985. Soil Chemistry. John Wiley \& Sons, New York, $341 \mathrm{pp}$.

Brunauer, S., P.H. Emmett and E. Teller, 1938. Adsorption of gases in multimolecular layers, J. Am. Chem. Soc., 60:309-319.

Carter, D.L., M.M. Mortland and W.D. Kemper, 1986. Specific surface. In Methods of Soil Analysis. Part 1: Physical and Mineralogical Methods, 2 nd ed. (Edited by A. Klute). Soil Science Society of America, Madison, WI, 413-423.

Davis, J.A. and K.F. Hayes, 1986a. Geochemical Processes at Mineral Surfaces, ACS Symposium Series, No. 323. American Chemical Society, Washington, D.C., 683 pp.

Davis, J.A. and K.F. Hayes, 1986b. Geochemical processes at mineral surfaces: an overview. In Geochemical Processes at Mineral Surfaces (Edited by J.A. Davis and K.F. Hayes), ACS Symposium Series, No. 323. American Chemical Society, Washington, D.C., 2-18.

Davis, J.A. and J.O. Leckie, 1978. Surface ionization and complexation at the oxide/water interface. II. Surface properties of amorphous iron oxyhydroxide and adsorption of metal ions, $J$. Colloid Interface Sci., 67:90.

Francis, B.M., 1994. Toxic Substances in the Environment. Wiley, New York, 360 pp.

Gregg, S.J. and K.S.W. Sing, 1982. Adsorption, Surface Area and Porosity. Academic Press, London, $303 \mathrm{pp}$.

Hayes, K.F. and J.O. Leckie, 1986. Mechanism of lead ion adsorption at the goethite-water interface. In Geochemical Processes at Mineral Surfaces (Edited by J.A. Davis and K.F. Hayes), ACS Symposium Series, No. 323. American Chemical Society, Washington, D.C., 114-141.

Hayes, K.F. and J.O. Leckie, 1987. Modeling ionic strength effects on cation adsorption at hydrous oxide/solution interfaces, J. Colloid Interface Sci., 115:564.

Hayes, K.F., C. Papelis and J.O. Leckie, 1988. Modeling ionic strength effects on anion adsorption at hydrous oxide/solution interfaces, $J$. Colloid Interface Sci., 125:717-726.

Hayes, K.F., A.L. Roe, G.E. Brown, Jr., K.O. Hodgson, J.O. Leckie and G.A. Parks, 1987. In situ $\mathrm{X}$-ray absorption study of surface complexes: selenium oxyanions on $\alpha-\mathrm{FeOOH}$, Science, 238:783.

Hochella, M.F., Jr. and A.F. White, 1990. Mineral-Water Interface Geochemistry, Reviews in Mineralogy, No. 23. Mineralogical Society of America, Washington, D.C., 603 pp. 
Katz, L.E. and K.F. Hayes, 1995. Surface complexation modeling: I. Strategy for modeling monomer complex formation at moderate surface coverage, J. Colloid Interface Sci., 170:477-490.

Klein, C. and C.S. Hurlbut, Jr., 1993. Manual of Mineralogy (after J.D. Dana). Wiley, New York, 681 pp.

McBride, M.B., 1994. Environmental Chemistry of Soils. Oxford University Press, New York, 406 pp.

McLean, E.O., 1982. Soil pH and lime requirement. In Methods of Soil Analysis. Part 2: Chemical and Microbiological Properties, 2nd ed. (Edited by A.L. Page, R.H. Miller, and D.R. Keeney), Soil Science Society of America, Madison, WI, 199-224.

O'Day, P.A., G.E. Brown, Jr. and G.A. Parks, 1994a. X-ray absorption spectroscopy of cobalt(II) multinuclear surface complexes and surface precipitates on kaolinite, J. Colloid Interface Sci., 165:269-289.

O’Day, P.A., G.A. Parks and G.E. Brown, Jr., 1994b. Molecular structure and binding sites of cobalt(II) surface complexes on kaolinite from x-ray absorption spectroscopy, Clays \& Clay Minerals, 42:337-355.

Papelis, C. and K.F. Hayes, 1996. Distinguishing between interlayer and external sorption sites of clay minerals using x-ray absorption spectroscopy, Colloids \& Surfaces, A, 107:89-96.

Sax, N.I., 1981. Cancer Causing Chemicals. Van Nostrand Reinhold, New York, 466 pp.

Sposito, G., 1984. The Surface Chemistry of Soils. Oxford University Press, Oxford, 234 pp.

Sposito, G., 1986. Distinguishing adsorption from surface precipitation. In Geochemical Processes at Mineral Surfaces (Edited by J.A. Davis and K.F. Hayes), ACS Symposium Series, No. 323. American Chemical Society, Washington, D.C., 217-228.

Stumm, W., 1992. Chemistry of the Solid-Water Interface. Wiley, New York, 428 pp.

Stumm, W., R. Kummert and L. Sigg, 1980. A ligand exchange model for the adsorption of inorganic and organic ligands at hydrous oxide interfaces, Croat. Chem. Acta, 53:291-312.

Yasunaga, T. and T. Ikeda, 1986. Adsorption-desorption kinetics at the metal-oxide solution interface studied by relaxation methods. In Geochemical Processes at Mineral Surfaces (Edited by J.A. Davis and K.F. Hayes), ACS Symposium Series, No. 323. American Chemical Society, Washington, D.C., 230-253. 


\section{APPENDIX A}

\section{EXPERIMENTAL DATA AND FRACTIONAL UPTAKE OF CO BY CABRIOLET SOIL}

pH Percent Adsorbed

\begin{tabular}{|c|c|}
\hline \multicolumn{2}{|c|}{$\mathrm{I}=0.1 \mathrm{M} ; \mathrm{Co}=10^{-6} \mathrm{M} ; \mathrm{a}=20 \mathrm{~g} / \mathrm{L} ; \mathrm{d}<1,180 \mu \mathrm{m}$} \\
\hline 2.63 & 16.88 \\
\hline 7.63 & 99.75 \\
\hline \multicolumn{2}{|c|}{$\mathrm{I}=0.01 \mathrm{M} ; \mathrm{Co}=10^{-6} \mathrm{M} ; \mathrm{a}=20 \mathrm{~g} / \mathrm{L} ; \mathrm{d}<1,180 \mu \mathrm{m}$} \\
\hline 2.61 & 37.55 \\
\hline 7.19 & 99.68 \\
\hline \multicolumn{2}{|c|}{$\mathrm{I}=0.1 \mathrm{M} ; \mathrm{Co}=10^{-4} \mathrm{M} ; \mathrm{a}=20 \mathrm{~g} / \mathrm{L} ; \mathrm{d}<1,180 \mu \mathrm{m}$} \\
\hline 2.61 & 22.01 \\
\hline 6.84 & 91.12 \\
\hline \multicolumn{2}{|c|}{$\mathrm{I}=0.1 \mathrm{M} ; \mathrm{Co}=10^{-4} \mathrm{M} ; \mathrm{a}=100 \mathrm{~g} / \mathrm{L} ; \mathrm{d}<1,180 \mu \mathrm{m}$} \\
\hline 6.98 & 98.94 \\
\hline \multicolumn{2}{|c|}{$\mathrm{I}=0.01 \mathrm{M} ; \mathrm{Co}=10^{-4} \mathrm{M} ; \mathrm{a}=20 \mathrm{~g} / \mathrm{L} ; \mathrm{d}<1,180 \mu \mathrm{m}$} \\
\hline 7.04 & 96.32 \\
\hline \multicolumn{2}{|c|}{$\mathrm{I}=0.1 \mathrm{M} ; \mathrm{Co}=10^{-6} \mathrm{M} ; \mathrm{a}=100 \mathrm{~g} / \mathrm{L} ; \mathrm{d}<45 \mu \mathrm{m}$} \\
\hline 7.02 & 99.84 \\
\hline \multicolumn{2}{|c|}{$\mathrm{I}=0.1 \mathrm{M} ; \mathrm{Co}=10^{-4} \mathrm{M} ; \mathrm{a}=20 \mathrm{~g} / \mathrm{L} ; \mathrm{d}<45 \mu \mathrm{m}$} \\
\hline 3.14 & 30.06 \\
\hline 7.00 & 96.87 \\
\hline \multicolumn{2}{|c|}{$\mathrm{I}=0.01 \mathrm{M} ; \mathrm{Co}=10^{-4} \mathrm{M} ; \mathrm{a}=20 \mathrm{~g} / \mathrm{L} ; \mathrm{d}<45 \mu \mathrm{m}$} \\
\hline 3.08 & 99.41 \\
\hline 6.98 & 98.31 \\
\hline 7.28 & 99.57 \\
\hline \multicolumn{2}{|c|}{$\mathrm{I}=0.01 \mathrm{M} ; \mathrm{Co}=10^{-4} \mathrm{M} ; \mathrm{a}=100 \mathrm{~g} / \mathrm{L} ; \mathrm{d}<45 \mu \mathrm{m}$} \\
\hline 7.04 & 99.63 \\
\hline
\end{tabular}




\section{APPENDIX B}

\section{EXPERIMENTAL DATA AND FRACTIONAL UPTAKE \\ OF CO BY LITTLE FELLER SOIL}

pH Percent Adsorbed

$\begin{array}{cc}\mathrm{I}=0.1 \mathrm{M} ; \mathrm{Co}=10^{-6} \mathrm{M} ; \mathrm{a}=20 \mathrm{~g} / \mathrm{L} ; \mathrm{d}<1,180 \mu \mathrm{m} \\ 3.59 & 49.64 \\ 6.94 & 99.30 \\ 8.54 & 100.00 \\ \mathrm{I}=0.01 \mathrm{M} ; \mathrm{Co}=10^{-6} \mathrm{M} ; \mathrm{a}=20 \mathrm{~g} / \mathrm{L} ; \mathrm{d}<1,180 \mu \mathrm{m} \\ 7.28 & 91.00 \\ 7.92 & 99.72 \\ 9.06 & 99.71\end{array}$

$\mathrm{I}=0.1 \mathrm{M} ; \mathrm{Co}=10^{-4} \mathrm{M} ; \mathrm{a}=20 \mathrm{~g} / \mathrm{L} ; \mathrm{d}<1,180 \mu \mathrm{m}$

$\begin{array}{ll}3.82 & 29.21 \\ 6.82 & 69.18 \\ 8.58 & 99.50\end{array}$

$\mathrm{I}=0.1 \mathrm{M} ; \mathrm{Co}=10^{-4} \mathrm{M} ; \mathrm{a}=100 \mathrm{~g} / \mathrm{L} ; \mathrm{d}<1,180 \mu \mathrm{m}$
8.00
97.55

$\mathrm{I}=0.01 \mathrm{M} ; \mathrm{Co}=10^{-4} \mathrm{M} ; \mathrm{a}=20 \mathrm{~g} / \mathrm{L} ; \mathrm{d}<1,180 \mu \mathrm{m}$

$$
8.59 \quad 97.47
$$

$\mathrm{I}=0.1 \mathrm{M} ; \mathrm{Co}=10^{-6} \mathrm{M} ; \mathrm{a}=20 \mathrm{~g} / \mathrm{L} ; \mathrm{d}<45 \mu \mathrm{m}$

$\begin{array}{ll}7.24 & 99.78 \\ 7.99 & 99.24\end{array}$

$\mathrm{I}=0.1 \mathrm{M} ; \mathrm{Co}=10^{-6} \mathrm{M} ; \mathrm{a}=100 \mathrm{~g} / \mathrm{L} ; \mathrm{d}<45 \mu \mathrm{m}$

$7.61 \quad 98.27$

$\mathrm{I}=0.01 \mathrm{M} ; \mathrm{Co}=10^{-6} \mathrm{M} ; \mathrm{a}=20 \mathrm{~g} / \mathrm{L} ; \mathrm{d}<45 \mu \mathrm{m}$

$7.17 \quad 99.22$

$8.01 \quad 99.98$

$\mathrm{I}=0.1 \mathrm{M} ; \mathrm{Co}=10^{-4} \mathrm{M} ; \mathrm{a}=20 \mathrm{~g} / \mathrm{L} ; \mathrm{d}<45 \mu \mathrm{m}$

$\begin{array}{ll}7.21 & 91.65 \\ 7.99 & 98.88\end{array}$

$\mathrm{I}=0.01 \mathrm{M} ; \mathrm{Co}=10^{-4} \mathrm{M} ; \mathrm{a}=20 \mathrm{~g} / \mathrm{L} ; \mathrm{d}<45 \mu \mathrm{m}$

$7.10 \quad 90.72$

$8.01 \quad 98.84$

$\mathrm{I}=0.01 \mathrm{M} ; \mathrm{Co}=10^{-4} \mathrm{M} ; \mathrm{a}=100 \mathrm{~g} / \mathrm{L} ; \mathrm{d}<45 \mu \mathrm{m}$

7.57

98.08 


\section{DISTRIBUTION}

Bob Bangerter

Environmental Restoration Division

Nevada Operations Office

U.S. Department of Energy

P.O. Box 98518

Las Vegas, NV 89193-8518

David Bedsun

Defense Nuclear Agency

Field Command

Nevada Operations Office

P.O. Box 208

Mercury, NV 89023-0208

Wayne Bliss

Bechtel Nevada Corporation

P.O. Box 98521

Las Vegas, NV 89193-8521

Joanne M. Bradbery, Director

Contracts Division

Nevada Operations Office

U.S. Department of Energy

P.O. Box 98518

Las Vegas, NV 89193-8518

Mary Lou Brown

International Technology Corporation

$4330 \mathrm{~S}$. Valley View

Suite 114

Las Vegas, NV 89103

Lee Davisson

Nuclear Chemistry Division

Lawrence Livermore National Laboratory

P.O. Box 808

$\mathrm{L}-237$

Livermore, CA 94550

Martha DeMarre

Chief, Document Research Section

Health Protection Dept.

Bechtel Nevada Corporation

P.O. Box 98521

Las Vegas, NV 89193-8521
Frank Di Sanza, Director

Energy Technologies Division

Nevada Operations Office

U.S. Department of Energy

P.O. Box 98518

Las Vegas, NV 89193-8518

Dave Dobson

1451 Harbor Bay Parkway

Alameda, CA 94502

Brian Dozier

Bechtel Nevada Corporation

P.O. Box 98521

Las Vegas, NV 89193-8521

Doug Duncan

Hydrology Program Manager

Office of Environmental Restoration

and Waste Management

Nevada Operations Office

U.S. Department of Energy

P.O. Box 98518

Las Vegas, NV 89193-8518

Donald Elle, Director

Environmental Protection Division

Nevada Operations Office

U.S. Department of Energy

P.O. Box 98518

Las Vegas, NV 89193-8518

Dennis Farmer

Radiation Sciences Laboratory

Office of Radiation and Indoor Air

U.S. Environmental Protection Agency

P.O. Box 98517, M/S 513

Las Vegas, NV 89193-8517

Joseph N. Fiore, Assistant Manager

Office of the Assistant Manager for

National Security

Nevada Operations Office

U.S. Department of Energy

P.O. Box 98518

Las Vegas, NV 89193-8518 
Clyde W. Frank

Assistant Secretary for Technology

U.S. Department of Energy

5B-014/FORS

Forresthall Bldg.

1000 Independence Avenue, SW

Washington, D.C. 20585

Larry Franks

Nevada State Health Department

Radiological Health Section

620 Belrose Avenue

Las Vegas, NV 89158

Joseph M. Ginanni

Waste Management Division

Nevada Operations Office

U.S. Department of Energy

P.O. Box 98518

Las Vegas, NV 89193-8518

Virginia Glanzman

U.S. Geological Survey

Box 2506, MS 913

Denver Federal Center

Denver, CO 80225

Roger Jacobson

Desert Research Institute

Water Resources Center

P.O. Box 19040

Las Vegas, NV 89132-0040

Marjory Jones

Desert Research Institute

Water Resources Center

P.O. Box 60220

Reno, NV 89506-0220

Jim Kannard

Bechtel Nevada Corporation

P.O. Box 98521

Las Vegas, NV 89193-8521

Randy Laczniak

U.S. Geological Survey

Water Resources Division

6770 S. Paradise Rd.

Las Vegas, NV 89119
Steve Lawrence

Engineering Division

Nevada Operations Office

U.S. Department of Energy

P.O. Box 98518

Las Vegas, NV 89193-8518

John Ledbetter

Contracts Division

Nevada Operations Office

U.S. Department of Energy

P.O. Box 98518

Las Vegas, NV 89193-8518

Steve Leedom

Test Operations Division

Nevada Operations Office

U.S. Department of Energy

P.O. Box 98518

Las Vegas, NV 89193-8518

S. John Mather

Assistant Secretary for Environment, Demonstration, Testing and Evaluation U.S. Department of Energy 472/TREV, Trevion Bldg. 1000 Independence Avenue, SW

Washington, D.C. 20585

Charles E. McWilliam, Director

Operations Management Division

Nevada Operations Office

U.S. Department of Energy

P.O. Box 98518

Las Vegas, NV 89193-8518

Steve Mellington, Director

Environmental Restoration Division

Nevada Operations Office

U.S. Department of Energy

P.O. Box 98518

Las Vegas, NV 89193-8518

Dr. Manoranjan Misra

Department of Chemical/Metallurgical

Engineering

MS 170

University of Nevada, Reno

Reno, Nevada 89557 
Beth Moore

Waste Management Division

Nevada Operations Office

U.S. Department of Energy

P.O. Box 98518

Las Vegas, NV 89193-8518

Paul Orkild

U.S. Geological Survey

Box 2506, MS 913

Denver Federal Center

Denver, CO 80225

James Owendoff

Assistant Secretary for Environmental Restoration

U.S. Department of Energy

5B-050/FORS

Forresthall Bldg.

1000 Independence Avenue, SW

Washington, D.C. 20585

Richard Pearl

Environmental Protection Division

Nevada Operations Office

U.S. Department of Energy

P.O. Box 98518

Las Vegas, NV 89193-8518

Stuart E. Rawlinson

ERWM

Bechtel Nevada Corporation

P.O. Box 95487, M/S 580

Las Vegas, NV 89193-5487

Ken Rehfeldt

Geotrans, c/o IT

4330 Valley View

Suite 112, MS-439

Las Vegas, NV 89103

Monica Salazar-Sanchez

Environmental Restoration Division

Nevada Operations Office

U.S. Department of Energy

P.O. Box 98518

Las Vegas, NV 89193-8518
Ralph Smiecinski

Energy Technologies Division

Nevada Operations Office

U.S. Department of Energy

P.O. Box 98518

Las Vegas, NV 89193-8518

David K. Smith

Isotopes Sciences Division

Lawrence Livermore National Laboratory

P.O. Box 808, M/S L231

Livermore, CA 94550

Joe Thompson

Los Alamos National Laboratory

INC-11, MS J514

P.O. Box 1663

Los Alamos, NM 87545

Doug Trudeau

U.S. Geological Survey

Water Resources Division

6770 S. Paradise Rd.

Las Vegas, NV 89119

Janet Wiley

International Technology Corporation

4330 S. Valley View

Suite 114

Las Vegas, NV 89103

\section{LIBRARIES}

Annie Kelley

State Documents Department

Nevada State Library

Capitol Complex

Carson City, NV 89710

Archives

Getchell Library

University of Nevada, Reno

Beverly Carter

MacKay School of Mines Library

University of Nevada, Reno

Document Section, Library

University of Nevada, Las Vegas

4505 Maryland Parkway

Las Vegas, NV 89154 
Library (Stead)

Desert Research Institute

P.O. Box 60220

Reno, Nevada 89506-0220

Library

IT Corporation

4330 S. Valley View

Suite 114

Las Vegas, NV 89103

ATTN: Toni Miller

Library

Southern Nevada Science Center

Desert Research Institute

P.O. Box 19040

Las Vegas, NV 89132-0040
Technical Information Resource Center

Nevada Operations Office

U.S. Department of Energy

P.O. Box 98518

Las Vegas, NV 89193-8518

Librarian

Water Resources Center Archives

$4100^{\prime} B$ Brien Hall

University of California

Berkeley, CA 94720-1718 